This PDF is a selection from a published volume from the National Bureau of Economic Research

Volume Title: A New Architecture for the U.S. National Accounts

Volume Author/Editor: Dale W. Jorgenson, J. Steven Landefeld, and William D. Nordhaus, editors

Volume Publisher: University of Chicago Press

Volume ISBN: 0-226-41084-6

Volume URL: http://www.nber.org/books/jorg06-1

Conference Date: April 16-17, 2004

Publication Date: May 2006

Title: Micro and Macro Data Integration: The Case of Capital Author: Randy A. Becker, John Haltiwanger, Ron S. Jarmin, Shawn D. Klimek, and Daniel J. Wilson

URL: http://www.nber.org/chapters/c0146 


\title{
Micro and Macro Data Integration The Case of Capital
}

\author{
Randy A. Becker, John Haltiwanger, Ron S. Jarmin, \\ Shawn D. Klimek, and Daniel J. Wilson
}

\subsection{Introduction}

It seems natural that statistical agencies would strive for internal consistency between macro- and microeconomic measures of key economic variables quantifying the activities of businesses. That is, ideally a given measure should be collected at the micro level (i.e., the firm or, even better, the establishment level) either from the universe of firms or from representative surveys, and macro aggregates of the measure should reflect appropriately weighted aggregation (e.g., sums or means) of the underlying microdata. Unfortunately, this ideal is achieved for very few of the key economic variables; the measures that come closest to this ideal are employment and

Randy Becker is a senior economist at the Center for Economic Studies of the U.S. Census Bureau. John Haltiwanger is a professor of economics at the University of Maryland, and a research associate of the Center for Economic Studies of the U.S. Census Bureau and of the National Bureau of Economic Research (NBER). Ron Jarmin is assistant division chief for research at the Center for Economic Studies of the U.S. Census Bureau. Shawn Klimek is an economist at the Center for Economic Studies (CES) of the U.S. Census Bureau. Daniel Wilson is an economist in applied microeconomic research at the Federal Reserve Bank of San Francisco.

This chapter was written, in part, by Census Bureau staff. It has undergone a more limited review than official Census Bureau publications. Any views, findings, or opinions expressed in this chapter are those of the authors and do not necessarily reflect those of the Census Bureau or the Federal Reserve system. All results were reviewed to ensure confidentiality. We thank Douglas Meade and Michael Glenn, Adriano Rampini, Andrea Eisfeldt, John Seabold, Robert Parker, and other participants at this NBER Conference on Research in Income and Wealth (CRIW) conference, and members of the Census Advisory Committee of Professional Associations, as well as seminar participants at the Center for Economic Studies for many helpful discussions concerning the various data sources used in this paper. We thank the participants of the NBER/CRIW preconference in August 2003 for their many helpful comments on the direction of this research. 
payroll. Measures of outputs and inputs are typically far from this ideal, even for nominal measures.

In this chapter, we focus on the measurement of capital stocks and flows, which are arguably the measures that are the furthest from this ideal. Specifically, we compare and contrast the measurement methodology for investment and capital at the aggregate (i.e., industry and asset) and micro (i.e., firm and establishment) levels. In so doing, we examine the extent of the micro/macro measurement inconsistencies and the associated limitations of both measurement and interpretation of capital dynamics at the micro and macro levels.

A key theme of this chapter is that the micro/macro inconsistency for capital measurement stems from dramatically different approaches to capital measurement at the micro and the macro levels. In the United States, aggregate capital measurement is based upon a top-down, supply-side approach. Production data for the capital goods producing industries, along with export and import data by product (asset) class yield measures of the domestic supply of each type of capital good. Measures of capital purchases/usage by government and consumers are then deducted from domestic supply to obtain gross investment totals by asset class. That is, gross investment totals are constructed using a commodity flow methodology that allocates the commodity totals among private and government consumption and fixed business investment. To construct a measure of the capital stock for each asset class, perpetual inventory methods are used that require the historical gross investment series, depreciation rates and investment price deflators by asset class.

Measuring economic (as opposed to accounting) depreciation and investment price deflators are difficult issues in their own right, but much of our focus is on other dimensions of capital measurement. Our analysis of aggregate capital measurement focuses on two closely related issues: (a) how the gross investment totals by asset class are allocated to industries and (b) how the gross investment measures by asset and industry classes from the top-down approach differ from the gross investment measures by asset and industry classes that can be constructed from a bottom-up approach. That is, there are data on capital expenditures in business surveys that can be aggregated to industry-asset totals as well.

Currently, the top-down approach for generating industry aggregates is based on the construction of capital flow tables that permit the allocation of the top-down asset totals to industries. The periodic capital flow tables (produced by the Bureau of Economic Analysis, hereafter BEA) are developed every five years as part of the input-output tables for the United States. Historically there have been limited data available to generate such capital flows tables and the BEA has, in lieu of direct information, used indirect methods and very strong assumptions to generate the capital flows tables. The limited information problem has been improved lately with the 
development of the Annual Capital Expenditures Survey (ACES), and the BEA has begun to incorporate the information from these data into their capital flows tables. However, for the most recent capital flow table released (i.e., the 1997 capital flow table, released in 2003), the BEA uses ACES data only to help construct the structures portion of the capital flows table and still uses indirect methods to construct the equipment portion of the capital flows table. At least part of the reason for this is that, as will become clear, it is difficult to reconcile the industry-asset statistics generated from the top-down and bottom-up approaches.

Another closely related focus of this paper is the nature and difficulties of measuring capital at the micro level. Increasingly, analysts interested in even macro issues seek to use firm-level data to understand the dynamics of key variables like productivity, job growth, and investment. Thus, getting capital measurement right at the micro level needs to be viewed as a critical part of the data infrastructure used to measure capital in the United States. In this paper, we review some sources of business-level data on capital and discuss the measurement methods that are available.

Even if the data are not fully reconcilable at the micro and macro levels, it is in principle desirable to have the measurement methodology be consistent. However, data limitations render this impossible. The aggregate approach uses perpetual inventory methods to construct capital stocks by asset (or industry-asset class). At the micro level, a number of limitations make this difficult. First, even though there has been progress via the development of ACES, data on investment by detailed asset are available at the firm level only periodically (currently every five years). The key annual business-level surveys (ACES and the Annual Survey of Manufactures) collect annual data on capital expenditures only by broad asset classes: equipment and structures. Second, business-level surveys have enormous sample rotation, especially for smaller businesses, and (as we will highlight below) underrepresent young businesses. These limitations make using perpetual inventory methods difficult at the broad asset class level and impossible at the level of detailed asset classes. Instead, a modified perpetual inventory approach is used to the extent possible, by initializing the capital stock based upon book value data when available and then using perpetual inventory methods for businesses that have sequential years of investment data. We examine the properties of the microdata in light of these limitations.

Another key theme of this chapter is that the internal inconsistency makes it very difficult to investigate the nature and sources of the variation in key economic variables. That is, given the internal inconsistency, it is not easy to drill down from the published aggregates to the microdata to investigate the (measurement or economic) factors generating the observed aggregate fluctuations.

For measurement reasons alone, it would be useful to be able drill down from the aggregates to the micro level. However, recent theory and empir- 
ical evidence from the micro behavior of businesses make clear that micro/ macro data integration may be essential for understanding the economic factors driving aggregate fluctuations. For example, recent evidence has emphasized that to understand macro aggregates it is important to measure and understand the contribution of the dynamics of the entry and exit of businesses (and in a related fashion the dynamics of young and small businesses). The basic reason is that the U.S. economy (like most advanced market economies) is constantly restructuring and this restructuring is associated with a large and continuing change in the composition of businesses. Entering businesses are quite different on a number of dimensions than the businesses that are exiting. Likewise, young and small businesses are quite different from large and mature businesses.

All of this restructuring is quite important for measuring and understanding economic change and, unfortunately, the economic aggregates published by the statistical agencies both neglect some important aspects of the contribution of this restructuring and typically do not permit quantifying the contribution of this restructuring. Part of the problem stems from the natural focus on large and mature businesses in the collection and processing of data by the statistical agencies. While large and mature businesses account for a very large share of the level of economic activity, the dynamics of entry and exit and the associated dynamics of young and small businesses account for a disproportionate share of the change in activity. This perspective suggests that measuring and understanding aggregate changes require a measurement approach that permits the decomposition of the contribution of different types of businesses (and not simply just along industry boundaries, but by entry and exit, young and mature, large and small). However, such decompositions require micro/macro consistency - that is, in the current context, to decompose the contribution of entering and exiting businesses to capital investment we would need to be able to quantify the capital investment of continuing, entering, and exiting businesses in an internally consistent manner. However, since the capital investment data are not internally consistent at the micro and macro levels, this approach is generally not possible. ${ }^{1}$

The chapter proceeds as follows. Section 12.2 provides a more detailed overview of capital measurement from the top-down (macro) and bottom-

1. A related argument is that recent evidence suggests that micro investment is a highly nonlinear function of fundamentals. Prima facie evidence for this is that investment at the micro level is highly skewed to the right and has a mass around zero and a fat right tail. It is unlikely that the distribution of shocks affecting businesses has this same shape (indeed, measures of the distribution of shocks at the micro level suggest that the distribution is approximately normal). The nonlinear nature of micro investment behavior implies that the response of aggregate investment dynamics to aggregate shocks will be complex and depend upon the crosssectional distribution of the circumstances faced across firms (see, e.g., Caballero, Engel, and Haltiwanger 1995). Viewed from this perspective, micro/macro consistency is fundamentally important for understanding the aggregate response of the economy to aggregate shocks. 
up (micro) approaches. The source data and measurement methods are discussed for both the micro and the macro approaches. Section 12.3 presents an analysis of some of the limitations of the top-down approach. The focus here is on the measurement of capital at the industry level and an analysis of the relationship between industry-level data from the top-down and bottom-up approaches. Analysis of the discrepancies at the industry level makes sense because the top-down and bottom-up approaches can both yield industry-level measures. Moreover, accurate industry level measurement is obviously critical for understanding the dynamics of the U.S. economy. For example, the adoption of advanced technologies like computers has been far from uniform across industries, and thus understanding the impact of changing technology depends critically on high-quality industry measures. Section 12.4 presents an analysis of the microdata with a focus on both the measurement limitations and the key properties of the distribution of capital and investment at the micro level. Alternative measurement methods and alternative data sources for micro measurement are presented and discussed. The last section provides concluding remarks.

\subsection{An Overview of the Measurement of Capital in the United States}

\subsubsection{Aggregate Capital Stocks and Flows: A Top-Down Approach}

The supply-side, top-down approach toward capital measurement utilizes production data from the capital goods-producing industries, data on capital exports and imports, and personal consumption and government use of capital goods. The primary source for the production data is the Census Bureau's Annual Survey of Manufactures (ASM), which collects data on a nationally representative sample of manufacturing establishments. The ASM collects information on the total value of shipments and inventories in nominal terms, and establishments are classified at the detailed industry (Standard Industrial Classification [SIC] and now North American Industrial Classification System [NAICS]) level. The Census Bureau also collects data on U.S. exports and imports via the U.S. Merchandise Trade Statistics, which uses a variety of sources (e.g., U.S. Customs, shipper's export declarations, etc.) to collect data on a detailed transaction basis of the products shipped and the countries of origin and destination. For capital goods industries, combining the shipments, exports, and imports data yields a nominal domestic use total by product (asset) class. Private and government consumption are subtracted from these commodity totals to obtain nominal use by the business sector.

Price deflators for these products are derived primarily from the Bureau of Labor Statistics' Producer Price Index (PPI; other sources include import/export price deflators). The BEA measures real gross investment by asset type as nominal investment divided by the appropriate price deflator. 
The capital stock for asset type $a$ is measured using a perpetual inventory specification given by

$$
K_{a t}=\sum_{j=0}^{\infty} \theta_{a j t} I_{a t-j}
$$

where $\theta_{a j t}$ provides the period $t$ weight for the vintage $j$ real gross investment of asset $a$ and $I_{a t-j}$ is the real gross investment of vintage $j$. The weights given to vintages depend upon whether the measure of the capital is to measure wealth or productive use. The BEA uses age-price (depreciation) profiles for its weights to construct its estimates of wealth by the perpetual inventory method. For the BEA, these weights emerge from assumptions that the depreciation patterns of most assets decline geometrically over time. In contrast, the Bureau of Labor Statistics (hereafter BLS) and the Federal Reserve Board (hereafter FRB) use age-efficiency schedules intended to capture the remaining productive value of assets of vintage $j$.

While the measurement of capital stocks and flows is already difficult enough, in large part because price deflators for capital goods are inherently difficult to measure, our focus (for the most part) is on the limitations associated with measuring capital stocks and flows at the industry level. ${ }^{2}$ To compute industry-by-asset gross investment totals, the BEA constructs data on the shares of each asset type in each industry's total investment.

Historically, there have been limited data available to produce these shares, and in lieu of direct measurement the BEA has used alternative indirect source data together with strong assumptions. In particular, the historical capital flows tables prior to 1997 are based upon information from the occupational distribution of employment (largely drawn from decennial census data) and strong assumptions about the relationship between the occupational and asset distributions (essentially fixed coefficient technology assumptions). Starting with the 1997 capital flows table (CFT; released in late 2003), the BEA has begun to incorporate industry-by-asset information from a direct survey of asset purchases by businesses (namely, the ACES). However, for the 1997 CFT (which will be the source of the in-

2. There is a very large literature on the measurement of depreciation and obsolescence. It is obviously of fundamental importance and also inherently difficult to measure. For the most part, this is not our focus, given our focus on micro/macro inconsistencies. However, one area of overlap is the role of entry and exit of businesses and the measurement of depreciation. Depreciation and obsolescence schedules are based upon service life distributions of assets. The latter reflect the physical service life of an asset, and to some extent the schedules reflect obsolescence via estimates from the secondary markets for capital (see, e.g., Hulten and Wykoff 1981). However, when businesses exit, the extent of irreversibility is unclear and the nature of secondary markets for businesses that are liquidated is in a related fashion unclear. To be fair, the BEA does provide an adjustment to its depreciation rates to deal with "selection bias," which significantly increases depreciation rates. However, the adjustment factors for selection are based upon limited information and provide little guidance to the role of exit across asset types, across industries, and over time. In our view, this is a neglected area of the measurement of depreciation and obsolescence, and our findings in section 12.4 below suggest that this could be important. 
dustry capital data for the last five years and the succeeding five years) the BEA only uses the structures detail data from the ACES. For the 1997 CFT equipment industry-by-asset shares, the standard method of using the occupational distribution of employment is used.

The BEA combines the industry-by-asset shares and the gross investment totals by asset to generate annual gross investment by industry and asset class. To provide more discipline on this allocation, the BEA uses industry expenditure control totals at a broad asset class (i.e., equipment or structures) from other sources (e.g., ASM and ACES) to produce its final statistics for capital stocks and expenditures by industry and asset classes reported in the CFT and the Fixed Reproducible Tangible Wealth (FRTW). ${ }^{3}$

To produce capital stocks (in the FRTW), the BEA uses the perpetual inventory approach using the industry-asset gross investment totals and the price deflators and depreciation profiles as described above. Since the FRTW is intended to reflect wealth and ownership of wealth, the depreciation profiles used reflect this conceptual objective. Adjustments are also made for the leasing versus ownership of capital (more on this in section 12.3 below).

The obvious micro/macro inconsistency in this top-down approach is that, for the most part, the CFT does not reflect actual data on the expenditures on assets by industries. Thus, by construction, there is a potential inconsistency between the business-level survey data on capital expenditures and the top-down-based measures. In section 12.3 below, we analyze the nature and extent of the discrepancies between the top-down and bottom-up approach.

Before proceeding to our discussion of the micro approaches to capital measurement, it is useful to emphasize that the U.S. statistical agencies have been at the lead of innovations to capital measurement. The adoption of hedonic methods for computers and the user cost approach for measuring capital in the 1980s are two examples. It is our hope that the U.S. statistical agencies will in turn take a lead in improving measures of the usage of capital and, in turn, the consistency between the micro and the macro measurement of capital.

\subsubsection{Business-Level Measurement of Capital:}

A Bottom-Up Approach

The U.S. Census Bureau conducts a number of surveys that provide data that can be used for capital measurement at the microeconomic level. The nature of these surveys has changed substantially over the last two decades, so it is useful to review the changes in the survey instruments.

3. The use of such control totals is complicated by the fact that the expenditure totals at even a broad asset level summed across all industries do not match up that well with the gross investment totals at a broad asset level from the top-down approach. As will become clear in section 12.3, this is one of several sources of difficulties in reconciling the top-down and bottom-up approaches. 
Statistical agencies historically have had the most complete and detailed measurement of capital at the business (micro) level in the manufacturing sector. The ASM, through 1987, collected data on book value at the beginning and end of year, new expenditures, used expenditures and retirements (including sales). In addition, all these items were collected separately for equipment and structures. Since 1987, the book value questions have been asked in the ASM only during economic census years (years ending in 2 or 7), and since 1997, the book value questions ask only about the total capital (rather than equipment and structures separately). Moreover, the retirement and sales questions have been dropped from the ASM. ${ }^{4}$ The ASM is an establishment-based survey, so measures of capital can obviously be constructed at the establishment level and then, through information in the Census Bureau's Business Register, can be aggregated to the firm level if desired.

For the nonmanufacturing sectors, data on book values and expenditures have historically been very sparse. In economic census years, a sample of nonmanufacturing businesses had been asked questions about their total book value of capital and total capital expenditures in the Asset and Expenditure Survey (AES). The sampling unit employed in the AES is not the establishment (as in the ASM), or the firm (as in the ACES). The AES sampling unit can be thought of as a taxpaying entity (i.e., a particular Employer Identification Number) or a line of business (e.g., a two-digit SIC) within a firm. Due to the difficulty in matching data across these different survey units, we choose not to use AES investment data in this study. ${ }^{5}$

Since 1993, the Census Bureau has been collecting capital stock and expenditures data on an economywide basis using ACES as the survey instrument. ${ }^{6}$ The ACES is a firm-level survey, although firms are asked to break out at least some of their responses on an industry basis (e.g., on a two- to three-digit SIC basis). The ACES collects data annually on capital expenditures (new and used) by broad asset class (i.e., equipment and structures) and periodically (e.g., 1998 and 2003) by detailed asset class. The ACES also collects total book value of capital and retirement/sales of assets.

One obvious use of these surveys is to generate expenditure totals (by either broad asset category or detailed asset classes) at the industry level. These expenditure totals by industry and broad asset category are used as control totals in the top-down approach discussed in section 12.2.1. Additionally, the industry-level data have been used in their own right to construct capital stocks by detailed industry for the manufacturing sector. For

4. The deterioration of the ASM in terms of capital measurement is unfortunate, as the expenditures and retirements/sales data have been used at the micro level successfully to analyze the capital adjustment processes across businesses (see, e.g., Caballero, Engel, and Haltiwanger 1995 and Cooper and Haltiwanger 2000). The type of analysis in these studies is no longer feasible.

5. See Doms, Jarmin, and Klimek (2004) for more detailed descriptions of the investment data and sampling units in the AES.

6. A pilot version of ACES was in the field prior to 1993. 
example, the NBER/CES/FRB productivity database relies on these data to produce capital stock estimates for four-digit SIC manufacturing industries for the 1958-96 period.

These business-level data have also been used extensively by the research community to study investment dynamics at the micro level (the ASM data have been used much more extensively than ACES to date). Several measurement challenges immediately arise in the use of these data for this purpose.

First, the historical availability of the microdata as well as the sample rotation of the surveys makes literally applying the perpetual inventory measurement specification in equation (1) impossible for all but a small subset of the largest survey units. Consider the ASM for which data are available for a much longer period of time than for ACES. The ASM data at the CES are available from 1972 to the present. For businesses that existed in 1972, the data are left-censored and there are a large number of manufacturing establishments in the ASM that are left-censored. In addition, the ASM sample rotation is every five years with only large establishments sampled with certainty across panels. As such, data for small establishments are typically left-censored in the first year of a five-year ASM panel and rightcensored in the last. To overcome these limitations, researchers have typically applied the following variant of the perpetual inventory measurement methodology:

$$
K_{e t}=\left(1-\delta_{i t}\right) K_{e t-1}+I_{e t},
$$

where $K_{e t}$ is the capital stock for a broad asset type for establishment $e$ at time $t, I_{e t}$ is real gross expenditures (ideally new plus used less retirement/ sales, but often just new plus used given lack of retirement/sales data), and $\delta_{i t}$ is the depreciation rate. ${ }^{7}$ The latter is indexed by $i$ and $t$ to denote that plant-level depreciation schedules are not available so the typical practice is to use the depreciation rate schedule for industry $i$ at time $t$. The depreciation rate at the industry level varies over time as the asset mix of an industry changes over time.

Several measurement difficulties are immediately apparent in imple-

7. The depreciation rates and the age-price or age-efficiency schedules from equation (1) are obviously closely related. A standard method for generating industry depreciation rates is to use equation (2) along with the real measures of capital and investment at the industry level to back out the implied rate of depreciation at time $t$ in industry $i$. Those researchers who use the implied depreciation schedules from the NBER-CES Productivity Database are using depreciation schedules that reflect the productive capital stock, since the NBER-CES Productivity Database relies upon age-efficiency schedules from the FRB. Note further that Caballero, Engel, and Haltiwanger (1995) and Cooper and Haltiwanger (2000) use the retirement/ sales data in their measures of gross capital expenditures. Use of the latter permits these studies to study the propensity for negative gross investment that is indeed observed in the data. However, these studies find that the distribution of gross investment rates is highly skewed to the right, with relatively little negative gross investment suggesting the presence of substantial irreversibilities. 
menting equation (2). Left-censoring implies that the capital stock needs to be initialized in the initial year of observation (rather than initial year of operation). The standard practice is to use the book value to initialize the capital stock. Typically, since book values don't reflect price and efficiency factors, there is a crude adjustment to this initial capital stock. The statistical agencies (e.g., BLS and BEA) produce capital stocks on a historicalcost and real basis (the real capital stock is measured using the methods described above) at an industry level. Microdata researchers often use this information to make the following adjustment of the initial capital stock:

$$
K_{e 0}=\frac{\mathrm{BV}_{e 0}}{\frac{\mathrm{BV}_{i 0}}{K_{i 0}}},
$$

where $\mathrm{BV}_{e 0}$ is the book value for the establishment in the initial year $0, \mathrm{BV}_{i 0}$ is the historical-cost value at the industry level (from BEA or BLS) for the industry $i$ that establishment $e$ is located in for year 0 , and $K_{i 0}$ is the real capital stock at the industry level (from BEA or BLS) for year 0 . This adjustment of the book value corrects for price and efficiency differences in the asset mix at the industry level but obviously generates mismeasurement for establishments within the same industry with different vintages and asset mixes.

In addition to the problem of initializing the capital stock, investment price deflators are typically not available at the establishment level either. Instead, researchers use the industry-level investment price deflator so that asset mix differences across establishments in the same industry also are a source of measurement error.

While implementation of this methodology for ASM establishments already raises various measurement issues, the problems are even more severe in attempting to measure real capital stocks and flows at the firm level with ACES. ${ }^{8}$ For one, given that ACES only started in 1993, the leftcensoring problem is large for even the businesses that are regularly sampled in ACES. For another, the sample rotation in ACES is annual so that for small businesses the adjusted book value (as in equation [3]) is the only measure of the capital stock available. In addition, ACES is a firm-level survey and only asks firms to break out industry data at a two- to threedigit level. As will become clear below, there are questions about the qual-

8. Another data source for firm-level capital stocks that has been widely used in the literature is the COMPUSTAT data. The methods for measuring capital stocks and flows from COMPUSTAT are typically very similar to the methods described in this section (with similar limitations). Future work needs to be done comparing and contrasting the ACES data with COMPUSTAT data as a further check on the quality of the ACES data. We do not focus on the COMPUSTAT data in this chapter since they reflect only publicly traded companies, so that the sample selection makes micro/macro comparisons not very informative. 
ity of the industry-level data in ACES, as firms apparently truncate the set of industries for which they should be reporting capital expenditures. Finally, and this is another theme we return to in section 12.4, ACES adds new businesses with a considerable lag. The paucity of data on new businesses raises a variety of questions. Among other things, new businesses are arguably quite different in the rate and mix of investment across asset classes. This heterogeneity is masked in the ACES since young businesses are undersampled.

This brief overview makes transparent that the micro and macro capital stock measures are not internally consistent. Even for nominal capital expenditures the micro and the macro data are not internally consistent, much less the real capital expenditures and real capital stocks. In what follows, we quantify and explore the nature of the micro and macro approaches on a variety of dimensions.

\subsection{Top-Down versus Bottom-Up: The Industry Allocation of Asset-Specific Investment}

One of the primary objectives of this chapter is to quantify the extent to which the top-down and bottom-up approaches to capital measurement differ. In this section, we focus on how the two approaches yield different allocations of asset-specific investment across industries. The primary set of data on investment flows by asset and industry is the CFT, constructed at five-year intervals by the BEA. We describe the methodology for constructing the CFT as "top-down" since the BEA first obtains economywide investment totals at the detailed asset level and industry investment totals at the broad asset level (equipment or structures), and then allocates detailed asset-level investment to using industries based not on micro expenditures data, but based rather on occupational employment data. As it is derived from the CFT, the BEA's annual investment by asset type and by industry data, the FRTW, can also be characterized as top-down. An alternative, bottom-up approach would be to aggregate up to the industry level from micro-level data on expenditures by detailed asset type. Until recently, this could not be done as such microdata did not exist. However, detailed asset-type investment data were collected in the 1998 ACES, allowing us to create a bottom-up investment-by-type-and-by-industry matrix.

Section 12.3.2 below describes a number of exercises we performed to quantify the differences and similarities between the BEA's top-down investment allocations and the bottom-up allocations we obtained from the 1998 ACES. The ACES itself is discussed in more detail in section 12.3.3, including some of its important limitations as well as potential remedies. First, though, we provide some necessary background regarding the construction of two BEA investment matrices and their conceptual differences. 


\subsubsection{Background}

\section{Conceptual Differences}

There are two substantial conceptual differences between the CFT and the FRTW. First, the CFT is on a use basis, whereas the FRTW is on an ownership basis. The distinction primarily has to do with how the two data sets treat operating leases. The CFT allocates leased capital to the lessee (user) industry while the FRTW allocates it to the lessor (owner) industry. The choice of treatment has an enormous impact on the distribution of certain types of capital goods such as autos, trucks, and aircraft.

The second conceptual difference is that the CFT measures only flows of new capital, whereas the FRTW seeks to track flows of used capital as well. For instance, for autos, the CFT provides estimates of each industry's use of autos produced in the current year. Purchases or leases of used autos would not be counted. In contrast, the FRTW attempts to first obtain each industry's expenditures on new and used autos and then net out the industries' sales of used autos to consumers or other industries (though, in practice, they can only net out sales to consumers since there is no data on interindustry transfers).

\section{Construction of the Capital Flows Table}

The methodology used by BEA to construct the CFTs in general, and the 1997 CFT in particular, is fully documented in Meade, Rzeznik, and Robinson-Smith (2003). Here we provide a brief synopsis. First, the BEA obtains asset-type (row) control totals (i.e., economywide investment by asset type), which are taken straight from the data on private fixed investment by asset type in the BEA's benchmark input-output (IO) tables. ${ }^{9}$ These totals are also published in the private fixed investment tables of the National Income and Product Accounts (NIPAs). For structures, data on private (nonresidential) fixed investment by type of structure comes from the Census Bureau's "Value of Construction Put in Place," which is based on a survey of builders of construction projects. For equipment, private fixed investment by asset in the IO tables is obtained from source data on domestic supply (shipments minus net exports), from which measures of private and government consumption are then subtracted. ${ }^{10}$ Thus, we refer to the CFT's approach to obtaining asset-type control totals as the "supplyside" approach.

Second, the BEA obtains industry (column) control totals from aggre-

9. For more information on the BEA's supply-side approach to obtaining asset investment totals, see Lawson et al. (2002).

10. For certain asset types, special adjustments are made to private fixed investment numbers. For example, for autos, a portion of consumers' purchases of autos is added to the business fixed investment total according to Census data on the average fraction of mileage consumers use their autos for business purposes. 
gated firm- or establishment-level data on capital expenditures (over all asset types). The primary sources of these data are the Economic Census (EC) and the ACES (after 1992) or the Plant and Equipment (P\&E) survey (before 1992). Note, however, that the ACES source data referred to here are those on total investment (available every year since 1992), not the data on investment by asset type (available only in certain years). The industry control totals, as derived from the source data, are adjusted for some industries so that expenditures on operating leases are allocated to the lessee (using) industry rather than the lessor (owner) industry.

Third, the asset-type control totals are allocated to using industries via two methods: "direct" and "distributive." With direct allocation, capital goods thought to be used by a small set of industries are directly allocated (in total) to those industries in proportion to their output. For example, mining and oil field equipment is distributed to the following industries: oil and natural gas extraction, coal mining, metal ores mining, nonmetallic mineral mining and quarrying, support activities for mining, and natural gas distribution. For capital goods thought to be used by multiple industries, their investment totals are distributed to using industries based on BLS data on occupational employment by industry. As Meade, Rzeznick, and Robinson-Smith (2003) describe it, "[c]ertain occupations or sets of occupations are assumed to be good indicators of which industries use a specific type of capital good; for example, machine tools are allocated to industries by the employment of machine tool operators." In the 1997 CFT, 85 percent of total new equipment investment was allocated to industries using this latter method. For the recently released 1997 CFT, investment for a subset of structures types (constituting 37 percent of total structures investment) was allocated using the published data on investment by industry and by asset type from the 1998 ACES. Prior to the 1997 CFT, these structures types were allocated to industries using the occupational employment data.

\section{Construction of the Fixed Reproducible Tangible Wealth investment matrix}

Now, consider the BEA's methodology for constructing the annual FRTW investment matrices. ${ }^{11}$ First, as with the CFT, they obtain "supplyside" asset-type control totals from the private fixed investment tables of the NIPAs. In contrast to the CFT, for some asset types, this total is then adjusted for net transfers of used capital into the business sector (from consumers, government, or foreign countries), which are estimated using various sources of data. In the case of autos, for example, sales of used autos to consumers by businesses (e.g., rental car companies) are estimated using auto registration data and subtracted from total business fixed investment in autos. 
Second, the BEA obtains industry control totals from aggregated firmor establishment-level survey data on capital expenditures. Starting with 1993 (the first year of the ACES), the survey data primarily consist of the ASM for manufacturing industries and the ACES (and sometimes the P\&E survey as well) for nonmanufacturing industries. For years before 1993, the BEA primarily uses the Economic Census for years in which it's available, and uses the ASM and P\&E survey for other years. Notice that for Economic Census years, the FRTW and CFT use essentially the same source data for industry control totals. However, a major difference in the CFT's and FRTW's industry control totals comes from the fact that the FRTW adjusts industry totals for transfers of used assets. For example, an industry's exports of used assets are subtracted from the industry's capital expenditures to arrive at the industry's investment total.

Third, asset-type investment totals are allocated to purchasing industries. The initial allocation is based on the adjacent CFT(s), which, as described above, are based on BLS occupational employment data. Since the FRTW is on an ownership basis and the CFT is on a use basis, this initial allocation is adjusted to an ownership basis "using data from unpublished I-O studies, industry trade associations, and secondary sources" (BEA 1999). For years between two CFTs, they interpolate the capital flows distribution. For years after the most recent CFT (1992 at the time of this writing), they extrapolate. ${ }^{12}$

\section{Uses of the BEA's Investment Matrices}

The importance of the BEA's data on investment distributions by industry and by capital type is far greater than is generally recognized. These distributions are frequently used in academic studies relating to the economic effects of industry information technology (IT) usage (see, e.g., Autor, Levy, and Murname 2003; Wolff 2002; Stiroh 2004; Wilson 2003). In fact, some studies even use these data to analyze the relationship between occupational mix and capital mix, which, given that the distributions are based on occupational mix in the first place, is rather disconcerting. These distributions are also used by other governmental and non-governmental data programs. For instance, these distributions provide the weights used (e.g., by the FRB, the BLS, and Jorgenson, Ho, and Stiroh 2005) to generate aggregate investment deflators from asset-specific price indices. These aggregate deflators, in turn, are used throughout empirical macroeconomics. Likewise, the distributions are also used by the BLS and others to generate measures of aggregate capital services by industry. The BLS uses these measures in their estimates of multifactor productivity (MFP). Lastly, the BEA's investment

12. Unfortunately, the version of the FRTW that makes use of the 1997 CFT was not released in time for use in our study. 
distribution data are used by businesses, academia, and the government to do forecasting, marketing studies, and impact analysis. ${ }^{13}$

\subsubsection{Comparing the Top-Down and Bottom-Up Investment Matrices}

Given the important and wide-ranging uses of the investment distribution data, evaluating their accuracy is crucial. Until recently, however, such an evaluation was difficult (if not impossible) as there was no alternative data to compare to, at least for the United States. That changed with the 1998 ACES, which collected firm-level ("bottom-up") data on investment by detailed industry and asset type. These data can be aggregated up and used to assess the accuracy of the BEA's investment matrices, built using their "topdown" methodology. In this section, we conduct such an assessment.

First, though, we must decide which BEA investment matrix to compare to the 1998 ACES-derived investment matrix. Since the ACES data are conceptually most comparable to the FRTW, given that both are ownership based and they pertain to the same year, this seems a natural place to start.

In order to assess the similarity of the ACES and FRTW investment matrices, we look at three statistical measures of similarity: correlation, distance, and cosine. We report only the correlation statistics here; the distance and cosine measures yielded virtually identical results (available from authors upon request).

The two investment matrices can be compared along either the industry dimension or the asset-type dimension. That is, let $V_{i j}$ denote investment by industry $i$ in asset type $j$. Let $v_{i j}$ denote an industry's investment share of some asset type:

$$
v_{i j}^{\text {Source }}=\frac{V_{i j}}{\sum_{i} V_{i j}} ; \text { where Source }=\text { FRTW or ACES. }
$$

One can compute a correlation (or other similarity index) for each asset type between the vectors $\left\{v_{i j}^{\mathrm{FRTW}}\right\}_{j}$ and $\left\{v_{i j}^{\mathrm{ACES}}\right\}_{j}$. Alternatively, one can define an asset type's investment share as

$$
S_{i j}^{\text {Source }}=\frac{V_{i j}}{\sum_{j} V_{i j}},
$$

and one can compute a correlation for each industry between the vectors $\left\{s_{i j}^{\mathrm{FRTW}}\right\}_{i}$ and $\left\{s_{i j}^{\mathrm{ACES}}\right\}_{i}$.

The mean and median (over industries) of the within-industry, crosstype correlations (see equation [5]) between the FRTW and the ACES are

13. See Meade, Rzeznick, and Robinson-Smith (2003) for a more thorough description of the uses of the CFT. 
Table 12.1

Summary of within-industry, cross-type correlations

\begin{tabular}{lcc}
\hline Correlations between investment shares from: & Mean & Median \\
\hline 1998 FRTW and 1998 ACES (raw) & & \\
Equipment & & \\
$\quad$ Unweighted correlations & 0.653 & 0.774 \\
$\quad$ Weighted correlations & 0.833 & 0.967 \\
Structures & & \\
$\quad$ Unweighted correlations & 0.816 & 0.960 \\
$\quad$ Weighted correlations & 0.882 & 0.999 \\
1998 FRTW and 1998 ACES-FRTW hybrid & & \\
Equipment & & \\
$\quad$ Unweighted correlations & 0.703 & 0.821 \\
$\quad$ Weighted correlations & 0.864 & 0.971 \\
Structures & & 0.960 \\
$\quad$ Unweighted correlations & 0.809 & 0.999 \\
$\quad$ Weighted correlations & 0.885 & \\
1997 CFT and 1998 ACES-FRTW hybrid & & 0.947 \\
Equipment & & \\
$\quad$ Weighted correlations & 0.835 & 1.000 \\
Structures & & \\
$\quad$ Weighted correlations & 0.928 & \\
\hline
\end{tabular}

Note: Mean and median are calculated over 59 industries.

given in table 12.1 (along with the mean and median for the other comparisons discussed below). The statistics for equipment and structures are reported separately. We find that the mean correlation over industries for equipment is 0.65 and the median is 0.77 . For structures, the mean is 0.82 and the median is 0.96 . If, in computing an industry's correlation, we weight asset types by their investment share (i.e., the average between the FRTW and ACES shares), the mean for equipment rises to 0.83 and the median rises to 0.97 . For structures, the mean rises to 0.88 and the median rises to (virtually) 1. Clearly, weighting helps since the FRTW and ACES tend to align more closely for asset types that are a larger share of investment. Furthermore, as the high median suggests, there are a fair number of industries with weighted correlations close to one.

However, there are also a fair number of industries with very low correlations. This can be seen in figure 12.1, which shows two histograms of weighted correlations over industries - one for within-industry correlations across equipment investment shares (panel A) and one for withinindustry correlations across structures shares (panel B). For the crossequipment-types correlations, forty of the fifty-nine industries had a correlation between 0.9 and 1.0. Nonetheless, a few industries had very low correlations: Metal Mining (correlation $=0.03$ ), Petroleum Refining $(0.28)$, Miscellaneous Manufacturing (0.55), Pipelines (0.06), Gas Transmission, Distribution, and Storage (0.05), Nondepository Credit Institutions (0.27), 

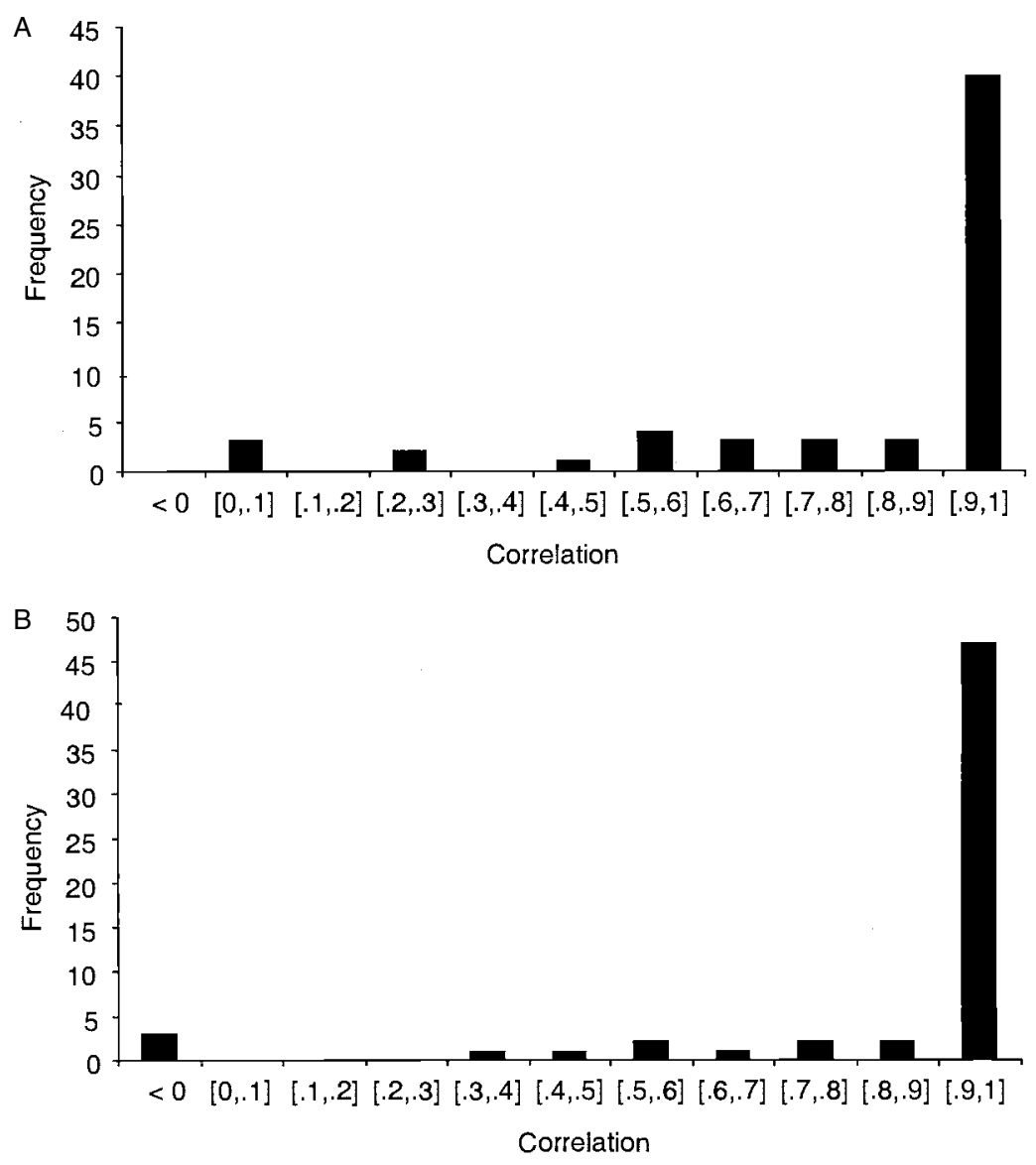

Fig. 12.1 FRTW versus ACES, within-industry, across-type correlations: $A$, Equipment; $B$, Structures

Security and Commodity Brokers (0.58), Insurance Agents, Brokers, and Service (0.43), Personal Services (0.53), and Repair Services (0.56). As for structures, there were fewer industries with very low correlations. Those that did have low correlations were Public Transportation (-0.07), Water Transportation (-0.11), Transportation Services (0.55), Real Estate Offices (0.47), and Health Services (0.33). Thus, it seems that there are still some substantial discrepancies between the FRTW and ACES.

Looking at the within-type, cross-industry correlations (see equation [4]), we find a mean of 0.68 and a median of 0.76 . If, in computing a type's correlation, we weight industries by their investment share, the mean rises to 0.79 and the median rises to 0.95 . Thus, the FRTW and ACES seem to have lower discrepancies for industries with larger investment (in each asset 
type). However, as with the within-industry correlations, there are still quite a few within-type correlations that are low. The especially low correlations were for the following types: Mobile Structures (correlation = 0.01), Educational Buildings (0.08), Religious Buildings (-0.02), Other Mining Exploration (0.03), Other Nonfarm Structures (0.15), Electrical Equipment, not elsewhere classified (0.10), Other Nonresidential Equipment (0.64), and General Purpose Machinery (0.65). The weak correlations for more general forms of equipment are not surprising since presumably it is difficult to identify which occupations intensively use such equipment. Apparently, there are some types of structures that are difficult to allocate across industries, but the outliers here don't appear to fit any general pattern. Also, given the wide use of the data on computer investment, it is worth noting that the unweighted correlation across industries for the computer investment share from FRTW and ACES is 0.76-the weighted correlation for computers is 0.81 . While this is a reasonably high correlation, it is far from one suggesting that those studies that use the computer investment by industry data from the FRTW are subject to potentially nontrivial measurement error that is, by construction, correlated with the distribution of occupations across industries.

\section{Which Is Right?}

From the results discussed above, we conclude that the BEA's "topdown" FRTW investment matrix and the "bottom-up" matrix derived from the ACES largely agree on the capital distributions for the most important asset types, but there are serious differences for particular industries and particular asset types. In the face of these discrepancies, the obvious question is: which is right?

Both have their advantages and shortcomings. Clearly, the primary advantage of the ACES investment matrix is that it is survey based - that is, bottom-up. In contrast, the allocation of asset-type investment to purchasing industries (i.e., the investment shares) in the FRTW is derived from the most recent CFT. In turn, the investment shares in the CFT are based on arguably suspect assumptions. Specifically, as described above, the CFT investment shares are based on assumed relationships between capital use of particular asset types and employment in particular occupations. We are aware of little or no empirical support for these relationships. ${ }^{14}$

The fact that ACES is survey based, however, doesn't mean that its data are necessarily entirely accurate. There are in fact a number of potential sources of reporting error in the ACES. First, due to incomplete records or lack of effort on the part of the respondent, firms may not break out their investment into every industry in which they operate (as they are instructed to do). Indeed, we know from matching ACES respondents to their corre-

14. In principle, one could match ACES microdata to the Occupation Employment Survey to test the strength of the fixed coefficients implicit in this allocation method. 
sponding Business Register (BR) records that there is such "industry truncation"- an issue we explore in more depth in section 12.3.3. An implication of this is that the BEA's industry control totals derived from ACES may be incorrect.

Similarly, ACES respondents may fail to fully break out their investment into all of the appropriate asset types. Unfortunately, we have no alternative data source with which to evaluate the extent of this "type truncation," nor do we have any way to treat it (as we do in the case of industry truncation). Third, firms may expense some of their expenditures, where the BEA would (properly) consider it capital investment. This may be particularly problematic for particular asset types, such as computers and software. ${ }^{15}$ Fourth, ACES does not allocate the investment done by nonemployers either by industry or by asset type. In 1998, capital expenditure by nonemployers accounted for some 10 percent of nationwide investment. Note that these last three issues should mainly affect the asset-type control totals in the ACES-based investment matrix rather than the industry allocations, though it is possible that some industries are more susceptible to these types of reporting errors than others.

The FRTW, on the other hand, may be more accurate when it comes to the asset-type control totals. The FRTW captures economywide investment by asset type using the supply-side approach, described above, which is based on micro source data on domestic supply (shipments minus net exports) combined with measures of government and personal consumption of each asset type. In principle, this approach captures expenditures on an asset type irrespective of how purchasing firms account for these expenditures.

Note that the supply-side approach is not above reproach: investment is computed as a residual (i.e., $I=Y-N X-C-G$ ). While $Y$ (shipments) may be relatively well measured, measurement error in any of the remaining components will also manifest itself in $I$. This certainly may impact some asset classes more than others - for example, assets in which personal consumption $(C)$ or government expenditure $(G)$ may be particularly difficult to measure, such as computers. Also, net exports $(N X)$ are subject to a host of potential measurement problems. Nonetheless, in this paper, we assume that the BEA's supply-side asset investment totals are more accurate than the ACES totals, given the shortcomings of ACES described above. However, further research on the accuracy of the supply-side approach would be useful.

It is clear that the asset-type control totals in FRTW and ACES differ greatly. Table 12.2 shows the ratio of economywide investment by asset type from the FRTW to that of ACES. In most cases, ACES has lower asset-type investment than does FRTW.

15. In 2003, the Census Bureau addressed this issue in its supplemental Information and Communications Technologies (ICT) survey, which elicited information from firms regarding their expensing of ICT equipment. Unfortunately, these data were not yet available at the time of this writing. 


\begin{tabular}{|c|c|c|c|}
\hline Asset type & $\begin{array}{l}\text { Ratio of } \\
\text { FRTW } \\
\text { to ACES } \\
\text { investment } \\
\text { by type }\end{array}$ & $\begin{array}{l}\text { Share of } \\
\text { economy- } \\
\text { wide } \\
\text { investment } \\
\text { in FRTW }\end{array}$ & $\begin{array}{l}\text { Share of } \\
\text { economy- } \\
\text { wide } \\
\text { investment } \\
\text { in ACES }\end{array}$ \\
\hline \multicolumn{4}{|l|}{ Structures } \\
\hline Other nonfarm buildings & 0.168 & 0.007 & 0.041 \\
\hline Mobile structures & 9.034 & 0.003 & 0.000 \\
\hline Hotels, motels, and inns & 1.847 & 0.068 & 0.036 \\
\hline Industrial buildings & 0.891 & 0.130 & 0.143 \\
\hline Office buildings & 1.156 & 0.180 & 0.152 \\
\hline Other commercial buildings, NEC & 0.821 & 0.137 & 0.163 \\
\hline Commercial warehouses & 1.304 & 0.048 & 0.036 \\
\hline Hospital and institutional buildings & 0.656 & 0.057 & 0.085 \\
\hline Amusement and recreational buildings & 1.727 & 0.029 & 0.016 \\
\hline Air, land, and water transportation facilities & 0.673 & 0.021 & 0.031 \\
\hline Telecommunications facilities & 0.435 & 0.030 & 0.068 \\
\hline Electric, nuclear, and other power facilities & 1.454 & 0.102 & 0.069 \\
\hline Educational buildings & 1.063 & 0.040 & 0.037 \\
\hline Religious buildings & 0.696 & 0.024 & 0.033 \\
\hline Other mining exploration & 0.314 & 0.005 & 0.015 \\
\hline Petroleum and natural gas wells & 1.500 & 0.106 & 0.069 \\
\hline Other nonfarm structures & 2.107 & 0.012 & 0.005 \\
\hline \multicolumn{4}{|l|}{ Equipment } \\
\hline Instruments & 1.799 & 0.053 & 0.035 \\
\hline Computer and peripheral equipment & 1.043 & 0.125 & 0.142 \\
\hline Office equipment except computers and peripherals & 2.096 & 0.031 & 0.017 \\
\hline Communications, audio, and video equipment & 1.366 & 0.121 & 0.105 \\
\hline Capitalized software purchased separately & 4.256 & 0.072 & 0.020 \\
\hline Fabricated metal products & 1.355 & 0.014 & 0.012 \\
\hline Metalworking machinery & 0.930 & 0.051 & 0.065 \\
\hline Special industrial machinery & 0.479 & 0.054 & 0.134 \\
\hline $\begin{array}{l}\text { Ventilation, heating, air-conditioning, refrigeration, } \\
\text { and other general purpose machinery }\end{array}$ & 1.425 & 0.049 & 0.041 \\
\hline Autos & 0.130 & 0.019 & 0.174 \\
\hline Trucks, buses, and truck trailers & 6.271 & 0.140 & 0.026 \\
\hline Aircraft & 0.926 & 0.030 & 0.039 \\
\hline Other transportation equipment & 0.458 & 0.014 & 0.036 \\
\hline Mining and oil field-machinery & 0.350 & 0.006 & 0.021 \\
\hline Engine, turbine, and power transmission equipment & 0.980 & 0.007 & 0.008 \\
\hline Electrical transmission and distribution equipment & 3.622 & 0.034 & 0.011 \\
\hline Electrical equipment, NEC & 3.805 & 0.021 & 0.006 \\
\hline Furniture and related products & 1.269 & 0.053 & 0.050 \\
\hline Agricultural equipment & 3.815 & 0.009 & 0.003 \\
\hline Construction machinery & 1.767 & 0.034 & 0.023 \\
\hline Service industry equipment & 2.070 & 0.022 & 0.013 \\
\hline Other nonresidential equipment & 2.727 & 0.037 & 0.016 \\
\hline
\end{tabular}

Note: $\mathrm{NEC}=$ not elsewhere classified. 
As for the FRTW's (or the CFT's) industry control totals, for most nonmanufacturing industries, the totals are actually based on the ACES microdata, so the industry totals for the FRTW matrix do not differ much from our ACES-based matrix.

\section{Creating a Hybrid Matrix Combining the Advantages of FRTW and ACES}

So clearly the ACES and FRTW investment matrices each have some advantages over the other. Can the advantages of each be combined to create a hybrid investment matrix that is conceptually superior to either individually? We believe they can. First, we can rescale the ACES investment matrix to have the same asset-type control totals as those in FRTW. This should address the last three shortcomings of the ACES investment matrix that we mentioned above - namely, type truncation, expensing, and nonemployer investment. And as for industry truncation, we've developed a methodology to help treat this problem. This is described below in section 12.3.3. These two corrections yield a 1998 ACES/FRTW hybrid that is potentially superior to both.

As earlier, we computed the within-industry, cross-type correlations between the investment shares from the hybrid matrix and those from the FRTW. The correlations are computed separately for equipment types and structures types. The mean and median across industries are reported in table 12.1, and the histograms (for equipment and structures, separately) are shown in figure 12.2. Not surprisingly, the correlations generally are higher than those between the FRTW and the original ACES matrix. Similarly, the mean and median of the within-type, cross-industry correlations are also higher when comparing FRTW to the hybrid than when comparing FRTW to the original ACES.

The individual correlations for each type and each industry are also generally higher between the FRTW and the hybrid than between it and the original ACES. However, there remain a number of asset types and a number of industries for which there are substantial discrepancies. The industries with the lowest correlations for equipment are Petroleum Refining (correlation $=0.36$ ); Stone, Clay, Glass, and Concrete (0.58); Pipelines (0.47); Gas Transmission, Distribution, and Storage (-0.01); Nondepository Credit Institutions (0.36); Insurance Agents, Brokers, and Service (0.39). Those with the lowest correlations for structures are Mining and Quarrying Nonmetallic Minerals (0.35); Tobacco (0.43); Public Transportation (-0.07); Water Transportation $(-0.10)$; Air Transportation $(-0.08)$; and Health Services (0.56). The types with the lowest crossindustry correlations are for these types: Mobile Structures (0.04); Educational Buildings (0.08); Religious Buildings (-0.02); Other Mining Exploration (0.03); Other Nonfarm Structures (0.17); and Electrical Equipment, not elsewhere classified (0.11).

In order to help assess which data source is more accurate, it is useful to 
A

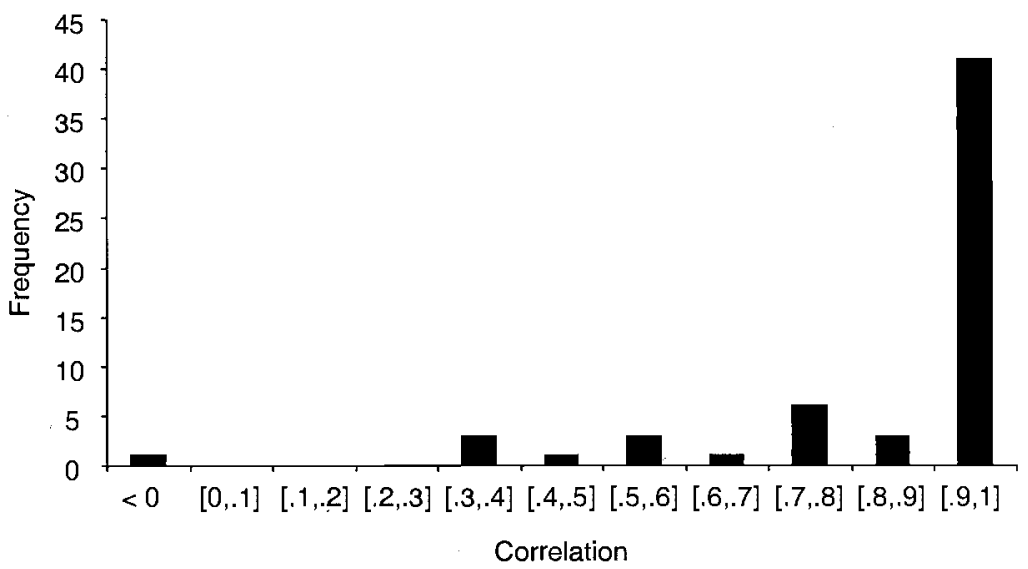

B

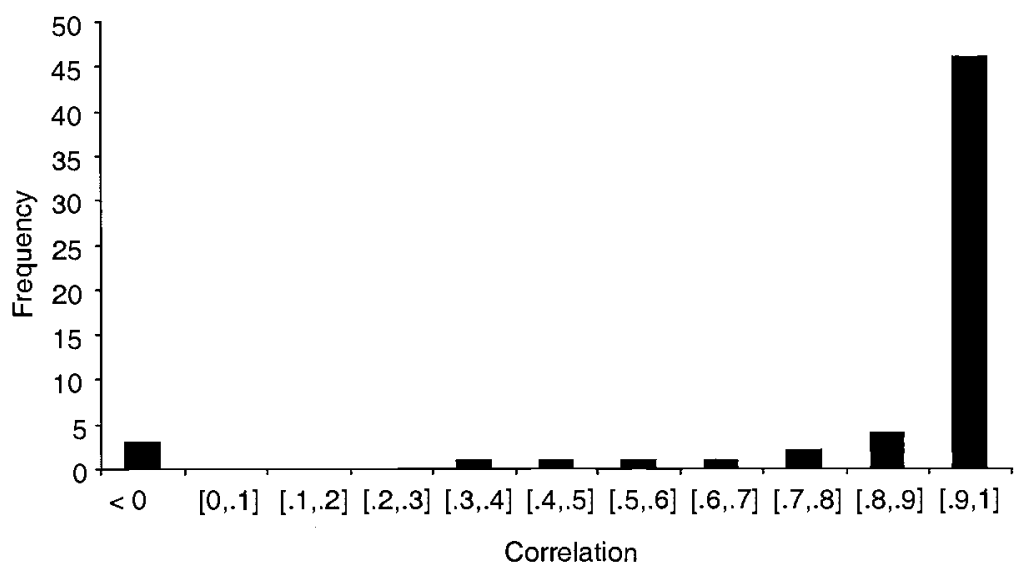

Fig. 12.2 FRTW versus ACES-FRTW hybrid; within-industry, across-type correlations: $A$, Equipment; $B$, Structures

look at an independent third source. One possible alternative source is the survey-based investment matrix constructed by Statistics Canada (StatCan). Table 12.3 shows the investment shares for selected asset-industry pairs from three sources: the FRTW, the FRTW-ACES hybrid, and StatCan. These selected pairs are every possible pair for which a common assettype and industry aggregate could be obtained (since each of the three sources has its own industry and type classification systems). Of the eightytwo comparable pairs that we obtained, StatCan was closer to the FRTWACES hybrid in terms of industry investment shares in fifty pairs (60 percent). In terms of asset type investment shares, StatCan was closer to the hybrid in forty-seven pairs (57 percent). The sum across all pairs of the absolute difference between StatCan's industry investment shares and those 


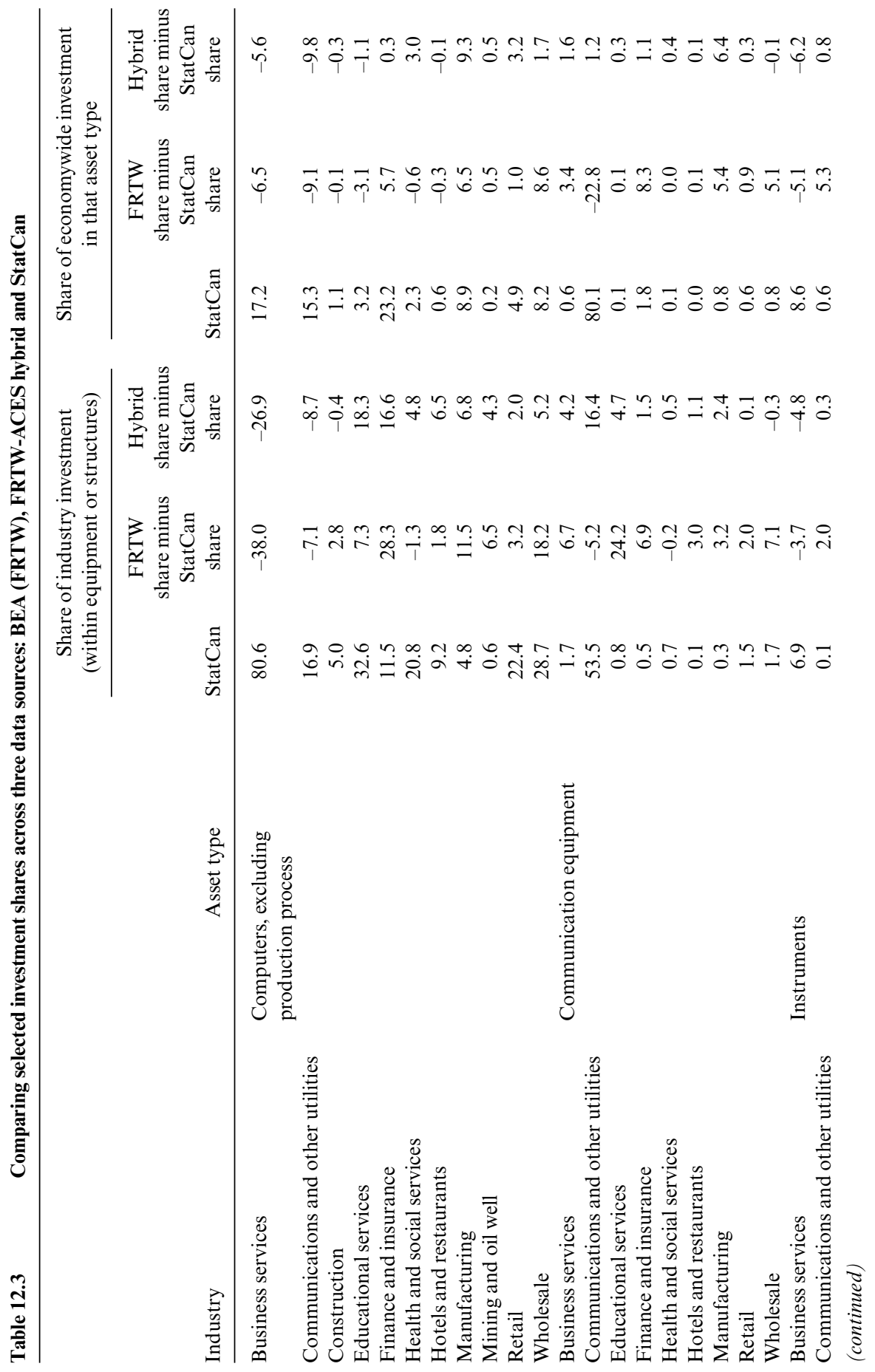




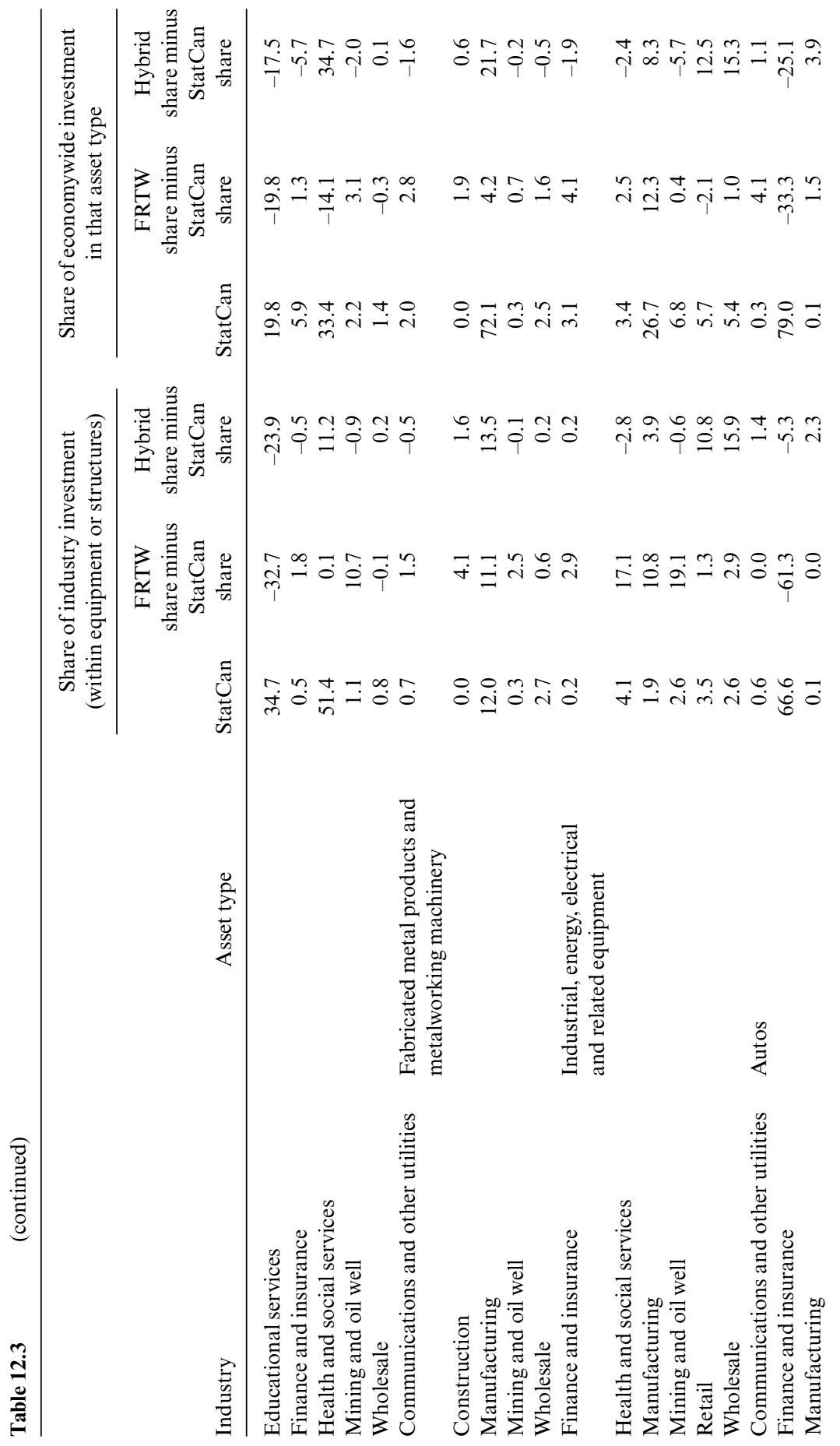




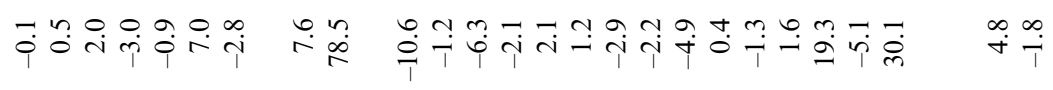

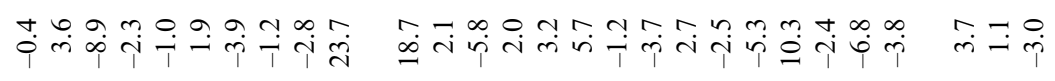

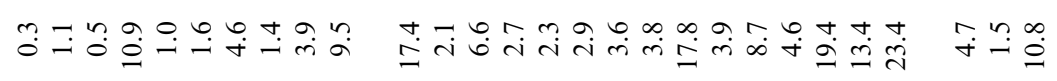

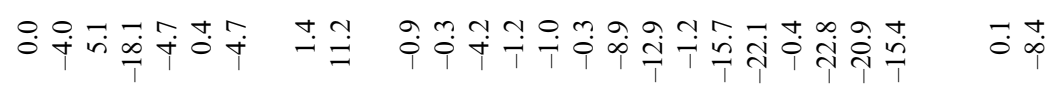

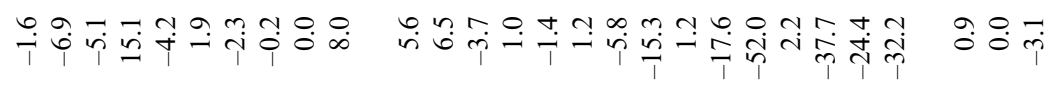

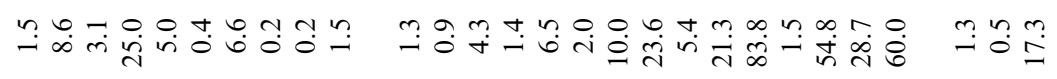
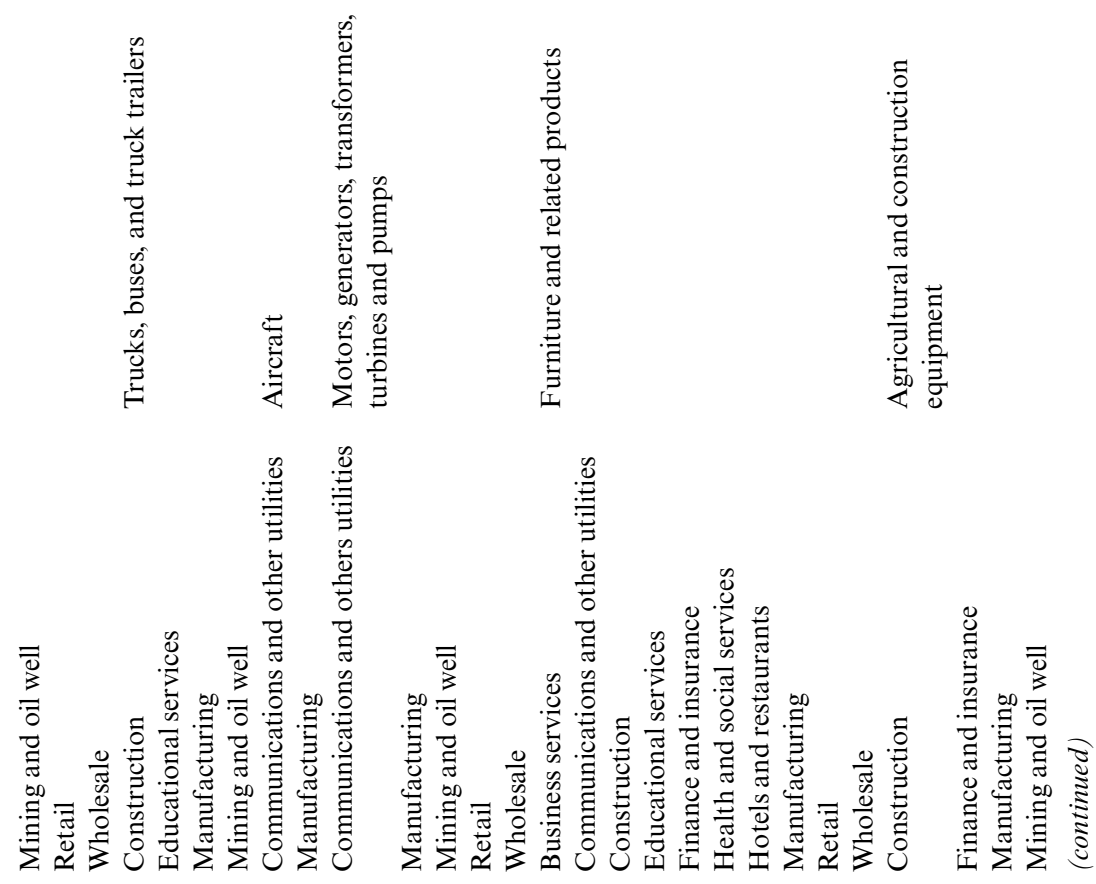


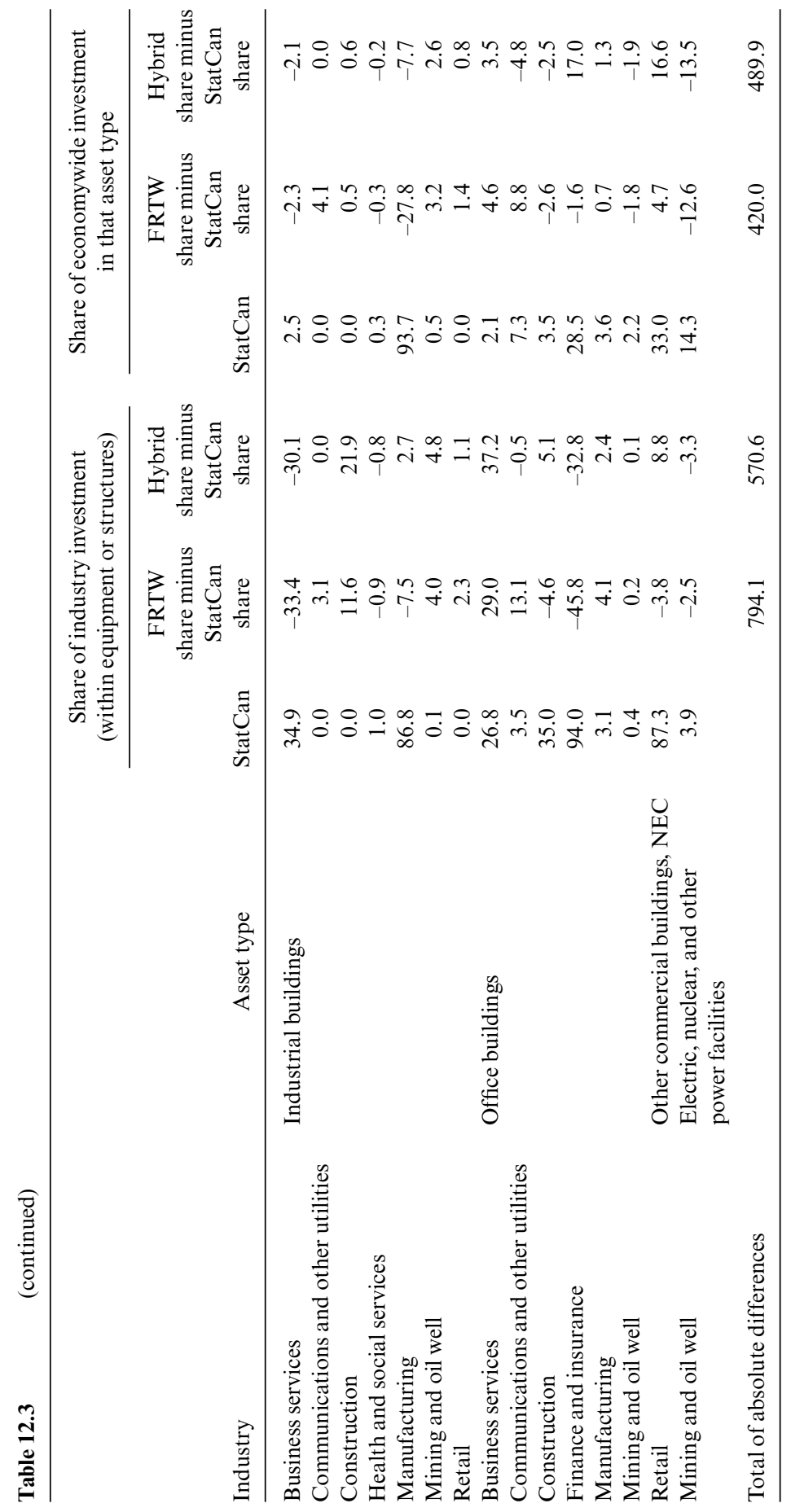


of FRTW turns out to be considerably larger than that between StatCan and the hybrid matrix. However, in terms of asset-type investment shares, the hybrid-StatCan differences are somewhat larger in total than the FRTW-StatCan differences.

Thus, in general, we find StatCan's investment distributions are more similar to the hybrid matrix than the FRTW. This begs the question: should the BEA use this hybrid instead of the current methodology for constructing FRTW?

The hybrid still is not immune to the ACES shortcoming of type truncation (which could explain agreement between the hybrid and StatCan, since StatCan may also be prone to similar type truncation). But this is arguably a smaller problem than the problems introduced by using occupational employment to allocate investment to industries. In fact, the BEA seems to be moving towards this hybrid, as indicated by the changes in methodology introduced in the 1997 CFT. With the 1997 CFT, investment in certain types of structures (covering 35 percent of structures investment) was allocated to industries according to 1998 ACES distribution. Ideally, we would like to compare this 1998 ACES-FRTW hybrid to a 1998 FRTW matrix that incorporates the 1997 CFT (not just because it uses the ACES distribution for some structures types, but also because it is based on more upto-date information). Unfortunately, these revised FRTW data were not available at the time of this writing.

So as an alternative, we can compare the 1998 hybrid matrix directly to the 1997 CFT. The shortcoming of this approach is that 1997 CFT is use based (where ACES is ownership based) and covers a different year. Nonetheless, in table 12.1 we show the mean and median of the correlations, and figure 12.3 presents the histograms. Not surprisingly, the correlations for structures are extremely high. In fact, the median correlation for structures is almost exactly 1 (and the mean is 0.93 ). For equipment, the median correlation is 0.95 and the mean is 0.84 . Thus, with the BEA's recent changes in methodology, the industry allocations of detailed asset investment have, in effect, partly switched from a top-down to a bottom-up approach, bringing increased consistency between micro and macro data on capital flows. However, for a fair number of important equipment types, large discrepancies remain between the ACES microdata and the CFT (and FRTW) macrodata. Further consideration by the BEA of using the ACES as a source for equipment investment allocations seems warranted.

In the section that follows, we introduce some of the key features of the ACES and further explore and discuss the issue of industry truncation, which (as we've noted) is an important limitation in using the ACES as a source of information about asset-industry shares and for building aggregate data. We discuss the methodology we've designed to treat the issue of industry truncation, and we demonstrate its effect on reallocating capital expenditure across industries and sectors. 

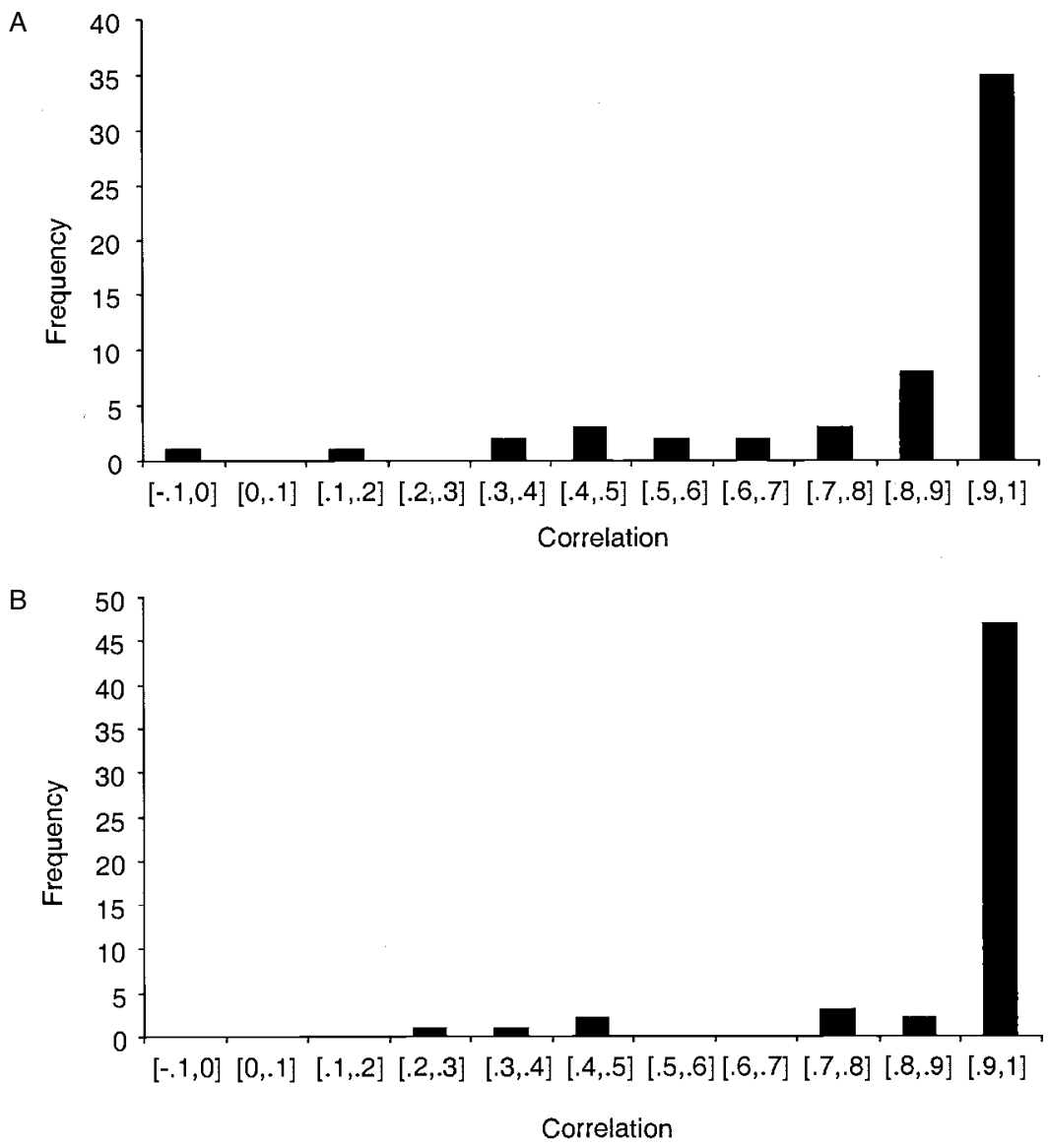

Fig. 12.3 CFT versus ACES-FRTW hybrid; within-industry, across-type correlations: $A$, Equipment; $B$, Structures

\subsubsection{Working with the Annual Capital Expenditures Survey}

In existence for over a decade, the ACES is a nationally representative firm-level survey designed to produce industry-level estimates of capital investment in new and used structures and equipment. ${ }^{16}$ Among our earliest discoveries in using the ACES microdata (and we are among the very first researchers to have used these data) is that firms may be providing insufficient industry detail on the ACES - that is, they "truncate" the list of industries that they record investment for. In particular, we noticed that many firms acknowledged far fewer industries on their ACES form than we observe employment and payroll data for in the Census Bureau's BR.${ }^{17}$ If

17. This observation relies on at least one critical assumption: If a firm had zero investment in an industry, it recorded the industry, reported zero, and the Census Bureau actually "keyed 
true, an implication is that ACES may incorrectly distribute total capital expenditures across industries, particularly if some industries are systematically excluded more often than others and the impacts are not perfectly off-setting.

\section{Correcting for Industry Truncation}

A description of the industry truncation (and details about the ACES survey in general) is located in the appendix, but in this section of the paper we attempt to correct the problem. To do so, we first assume that the information in the BR reflects a firm's true industrial composition. We then split the sample into two: "Complete reporters" are those firms whose list of industries on the ACES is absolutely identical to their list of industries in the BR. We employ these particular firms' ACES and BR data to compute investment-to-payroll ratios for each asset type and industry pair, simply calculated as total weighted capital expenditure in that industryasset pair divided by total weighted payroll in that industry. All other firms are designated "incomplete reporters" and their capital expenditures will be reallocated across industries using (a) their industry-level payroll from the BR and (b) the investment-to-payroll ratios computed from the com-

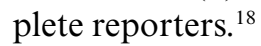

Specifically, for incomplete reporters with nonzero expenditure in a particular asset type, we sum up their investment in that asset to the firm level. We then completely replace the industries they recorded on the ACES with the list of industries they have payroll in according to the BR. We then multiply the payroll in these industries by the investment-to-payroll ratios specific to the asset-industry pair. This yields a firm-level capital expenditure that should not be used directly - it is the implied distribution of investment across industries that we are interested in, however. We use this distribution to allocate the actual firm-level capital expenditure in said asset type to the full list of BR industries for the firm. Should this particular methodology fail-as will be the case when the investment-to-payroll ratio is zero

in" at least the industry (if not also the zero). We know from other Census Bureau surveys, however, that zeros are often not keyed into the database (because they do not impact aggregation). By extension, in order to conserve time and resources, the Census Bureau may not key in a line of data from an ACES form if it contributes nothing to the aggregate capital expenditure. That industry entries do sometimes appear in the ACES database with zero investment suggests that the Census Bureau does sometimes key in such data. But the prevalence of missing data in the database also suggests that - just like in other surveys - zeros are very often disregarded in the ACES. For our purposes, we assume that if the database shows any trace of an industry associated with a firm then the firm in fact "acknowledged" that industry and we backfill zeros into the missing values as appropriate.

18. Actually, we allow firms to cross the boundaries of these groups on an asset-by-asset basis. Suppose, for example, that a firm reports zero investment in metalworking machinery in five industries. And say that the firm in fact truncated its industry detail-it actually operated in those five industries plus three others. Because we assume that firm-level totals are correct, capital expenditure in metalworking machinery in the three omitted industries must also be zero. This firm, and its eight industries, will enter the complete reporter group for at least this one asset type. 
for all of a firm's industries - we instead use the distribution of payroll to allocate capital expenditure across industries. The end result is a new distribution of capital expenditures across industries by detailed asset type, which served as the basis for the hybrid ACES-FRTW matrix we discussed and used in Section 12.3.2.

One can certainly imagine more refined reallocation mechanisms than the one used here. One of the less desirable features of the current algorithm, for example, is that a report of zero investment in a particular asset for a particular industry may be overwritten with a positive value, or a positive value may be replaced with an even larger value. Yet neither of these changes has anything to do with the problem of industry truncation per se. In principle, constraints can be placed on this type of reallocation, but these are rather difficult to implement empirically, for a variety of reasons. We have also experimented with the possibility of imputing zero investment for a particular firm's investment in a particular asset in a particular industry, recognizing that investment is often "lumpy" at the micro level. ${ }^{19}$ This too is quite difficult to implement empirically and if done improperly may lead to unintended biases. So while we acknowledge that more sophisticated methodologies certainly exist, much more understanding of their side effects is necessary. Therefore, for now, we have chosen a simple and (arguably) more benign treatment.

We are also intentionally conservative-along a number of dimensions - in our approach to reallocating capital expenditure. Because we are mainly interested in matching ACES to the BEA's FRTW and CFT, we first collapse the ACES data down to the lowest common denominator of industrial classification, reducing the number of industries from some ninety-eight down to sixty-three. One effect of this is that there are fewer mismatches between the ACES and the BR. ${ }^{20}$ Similarly, we aggregate asset types to the lowest common denominator, which reduces the fifty-five ACES types to forty. ${ }^{21}$ The net effect of both of these actions is larger

19. In essence, this variation of the algorithm would use the group of complete reporters to compute a probability of nonzero investment and an investment-to-payroll ratio conditional on investment being positive. This probability and conditional ratio would then be applied to the incomplete reporters. In a further refinement, the probability of investment could be set to one (zero) in cases where the firm already reports positive (zero) capital expenditure. And to remove the element of chance from the resulting estimates, this exercise can be replicated a number of times and an average of the outcomes taken.

20. For instance, suppose a firm reports its activity in chemicals (SIC 289) on the ACES but not drugs (SIC 283). Because the BEA recognizes no distinction within SIC 28, these data are collapsed. Therefore, the firm is seen as reporting data in SIC 28, which matches what is found in the (collapsed) BR, and is classified as a complete reporter, where normally it would not have been.

21. For example, office, bank, and professional buildings are combined with medical offices. Note that there are also instances in which the BEA recognizes more asset detail than the ACES - for example, the eight different types of computer and peripheral equipment. And there are two asset types that the ACES do not recognize at all: custom software and own-account software. This changed with the 2003 ACES. 
samples in the asset-industry cells, resulting in more robust estimates of investment-to-payroll ratios. ${ }^{22}$

For various reasons, we also decided not to reallocate capital expenditures in Cars and Light Trucks. Like the CFT, ACES measures just the flow of new capital, ignoring the sale of used capital. This is a very important distinction for asset types with extensive resale markets, as is the case with automobiles. To demonstrate the importance of this distinction: ACES tallies over $\$ 98$ billion of business investment in automobiles in 1998 (a total that does not include expenditure by nonemployers) while BEA's FRTW, which does adjust for resales, recognizes just $\$ 12.8$ billion. Surely some industries play more of a role here than others. For example, rental car agencies (SIC 751) invest heavily in automobiles but also sell off a tremendous number, generally after a few years of use. (Automobiles leased by the automakers face a similar fate.) FRTW reports $\$ 4.8$ billion of investment in automobiles by all of SIC 75 (Auto Repair, Services, and Parking), while firms in the ACES reported \$27.9 billion of (weighted) automobile investment in this industry - a difference of over $\$ 23$ billion. ${ }^{23}$ We found that reallocating automobiles needlessly contaminated our analyses (particularly in certain industries) and we therefore left them in their original industries.

\section{The Reallocation of ACES Capital Expenditure}

Despite our rather conservative approach to treating the industry truncation issue, we see some significant reallocation of capital expenditure across industries and sectors. Table 12.4 shows the reallocation of capital expenditure across broad sectors (in millions of 1998 dollars). Interestingly, the sector that gained the most from reallocation was Wholesale Trade, while Manufacture of Durable Goods lost the most. In light of our discussion in the appendix of industry truncation at manufacturing firms, these findings are not at all surprising. Besides Wholesale Trade, other sectors gaining large amounts of capital expenditure are Transportation, Finance, and Manufacture of Nondurable Goods. Other sectors losing large amounts of investment are Services; Insurance and Real Estate; and the ACES category "serving multiple industries." A virtue of our algorithm is that capital expenditure in the latter is actually allocated to industries.

22. Though not our interest here, if assets were further collapsed into two types-equipment and structures - one could introduce investment-to-payroll ratios that varied by industry and size class. In early work with the 1995 ACES (not reported here), we did exactly that.

23. Interestingly, firms that are classified as primarily in SIC 75 in the ACES reported over $\$ 20$ billion in "retirements and dispositions" of capital assets, which presumably includes the sale of used autos. Since this is based on firm-level totals, however, this value may also include any retirement of nonautomobile assets as well as the retirement of assets these firms may have had outside of SIC 75. And the retirement of automobiles in this industry by firms not primarily engaged in this activity is excluded from this figure. Nonetheless, we see that this magnitude is similar to the \$23 billion gap between FRTW's and ACES's estimates of automobile investment in this industry. 
Table 12.4

Reallocation of capital expenditure by sector

\begin{tabular}{lc}
\hline Sector & Millions of 1998 dollars \\
\hline Agricultural services, forestry, and fishing & +61 \\
Mining & $-1,008$ \\
Construction & +98 \\
Manufacturing (nondurables) & $+1,615$ \\
Manufacturing (durables) & $-5,074$ \\
Transportation & $+7,395$ \\
Communications & $-1,127$ \\
Utilities & -609 \\
Wholesale trade & $+8,641$ \\
Retail trade & -252 \\
Finance & $+2,000$ \\
Insurance and real estate & $-4,074$ \\
Services & $-5,013$ \\
Health services & +111 \\
Serving multiple industries & $-2,766$
\end{tabular}

Underlying table 12.4 is a much larger table by detailed industry and detailed asset type (not presented here). This table reveals that the reallocation of the $\$ 8.6$ billion of capital expenditure toward Wholesale Trade is unusually broad, in the sense that nearly every asset type experienced a net gain in expenditure. This sort of robust reallocation does not appear to be the norm in other industries experiencing large net changes.

For example, in terms of the increase in investment in the transportation sector, roughly half of the $\$ 7.4$ billion is accounted for by the industry Motor Freight Transportation and Warehousing (SIC 42), which had most of its increase from nonautomobile transportation equipment. In the finance sector, Holding, Charitable Trusts, and Other Investment Offices (SIC 67), in particular, experienced a large increase in capital expenditure, most of which was in commercial buildings. Meanwhile, in the Manufacture of Nondurable Goods sector, the industry experiencing the largest gain was Chemicals and Allied Products (SIC 28), mainly in industrial buildings. It is important to note that not all industries in a sector necessarily move in the same direction. Food and Kindred Products (SIC 20), for example, experienced a decrease similar in magnitude to the increase in Chemicals, chiefly through a loss of miscellaneous equipment.

In terms of the sectors experiencing large losses of capital expenditure as a result of reallocation, Manufacture of Durable Goods leads the list. Here we find that Communications Equipment and Electronic Components and Equipment (SIC 36) are the largest of the losers, mostly in various types of industrial equipment. Again, however, there is heterogeneity within the sector; for instance, Primary Metals (SIC 33) experiences substantial gains. The decline in investment in the Service sector comes mainly in Business 


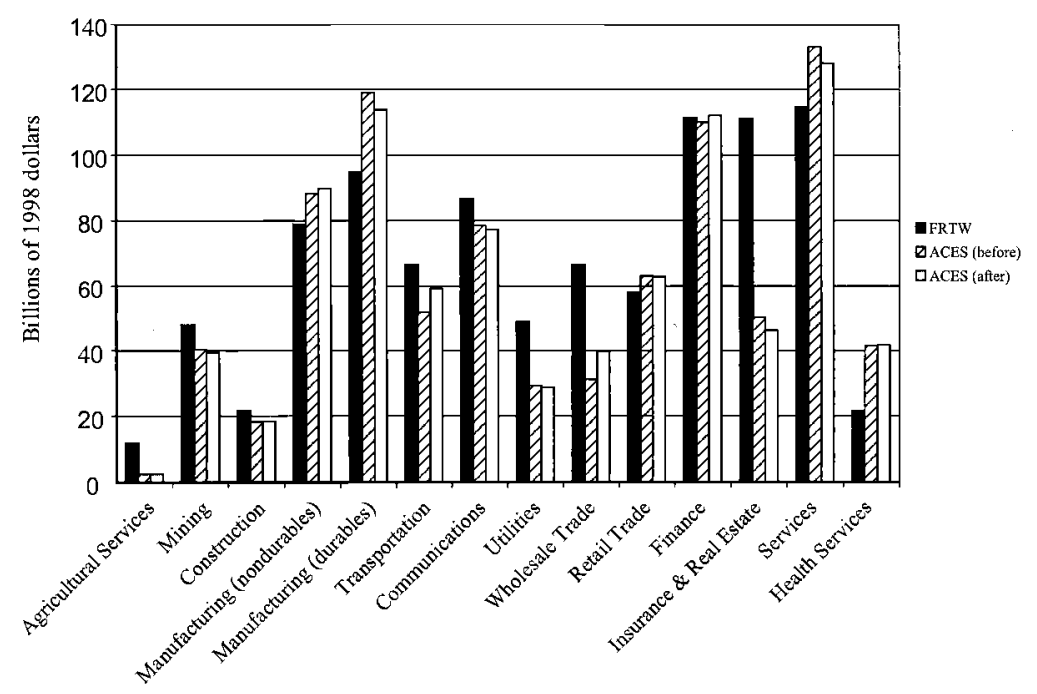

Fig. 12.4 Total capital expenditures

Services (SIC 73) and Automotive Repair, Services, and Parking (SIC 75), and the vast majority of that are accounted for by a decline in nonautomobile transportation equipment. And in the Insurance and Real Estate sector, Real Estate Offices (SIC 65) are found to lose a large amount of capital expenditure in commercial buildings.

Finally, in figure 12.4 we show how these reallocations affect sectoral totals vis-à-vis BEA's FRTW. This is done for the assets and industries that ACES and FRTW have in common. ${ }^{24}$ We see that our reallocation efforts moved ACES noticeably closer to FRTW totals in Manufacturing (Durables), Transportation, Wholesale Trade, and Services, but large differences still exist, particularly in Insurance and Real Estate, Wholesale Trade, Health Services, Utilities, and Manufacturing (Durables). Part of these discrepancies might be due to remaining conceptual differences. First, recall that capital investment by nonemployers (totaling $\$ 95$ billion in 1998) are not included in ACES totals, which may certainly explain at least part of the gap seen in an industry like Insurance and Real Estate. Second, ACES

24. In particular, ACES does not recognize investment in two types of software, nor does it tally capital expenditure for Agricultural Production (SIC 01-02). FRTW, on the other hand, does not contain capital expenditure for Combination Electric and Gas, and Other Utility Services (SIC 493), Water Supply (SIC 494), Steam and Air-Conditioning Supply (SIC 496), Irrigation Systems (SIC 497), and Social Services (SIC 83). Neither recognizes the U.S. Postal Service (SIC 43), Private Households (SIC 88), and Public Administration (SIC 9). With these restrictions, the FRTW contains \$939.9 billion in capital expenditure in 1998 while ACES contains $\$ 860.1$ billion. These totals cannot be easily compared because conceptual differences still remain. 
does not attempt to adjust for the sale of used capital, which we know from our example above amounts to $\$ 23$ billion in just one particular service industry. Third, there may be issues with the expensing of capital expenditure by firms in the ACES. And then there are the issues surrounding leasing. Therefore, while our correction for industry truncation in the ACES may matter, it is not the whole story.

\subsection{Business-Level Capital and Investment: A Bottom-Up Approach}

High-quality business surveys on capital stocks and flows are critical for building aggregates from the bottom up, but the microdata are also critical for understanding the behavior of investment at the micro and the macro levels. The longitudinal business datasets developed in the United States have increasingly been used by analysts to study the behavior of productivity, investment, employment, and price and wage dynamics. Part of the motivation for analysts to use such microdata is obvious, as the decisionmaking unit is the firm or the establishment. Therefore, testing alternative economic models of business behavior is best achieved with microdata. Aggregate data (at the industry- or economywide level) can only be used if firms within a given industry are relatively homogeneous in their behavior. However, the recent literature using microdata shows that micro- and macrodata provide very different pictures of investment dynamics. Macro investment dynamics are volatile in the sense that investment is highly procyclical but the aggregate data changes over a relatively narrow range of investment rates and in a smooth fashion. In contrast, investment at the micro level is very lumpy - there is a mass of businesses with zero or little investment and a fat right tail of businesses that exhibit what has been denoted an investment spike (see, e.g., Caballero, Engel, and Haltiwanger 1995; Doms and Dunne 1998; and Cooper, Haltiwanger, and Power 1999). Recent literature emphasizes that lumpy micro behavior implies complex aggregation. That is, movements in the aggregates will reflect both intensive and extensive margins, with the latter reflecting businesses discretely switching from inaction to action ranges for investment.

In this section, we explore the properties of the micro distribution of investment using the two key business-level surveys the Census Bureau uses to collect data on capital stocks and flows - the ASM and ACES. Our primary goal is to illustrate key properties of the micro distribution that highlight the idiosyncratic features of the micro distribution with a particular focus on those features that raise questions about aggregation and aggregate fluctuations. As noted in section 12.2.2, data limitations in these surveys unfortunately make it difficult to apply exactly the same measurement methodology (e.g., perpetual inventory) used in constructing investment rates using aggregate data. Instead, either an adjusted book values or a modified perpetual inventory method is used to construct capital stocks 
(and in turn act as the denominator in calculating an investment rate). As such, we also explore the sensitivity of the distributions at the micro level to these measurement issues.

\subsubsection{The Annual Survey of Manufactures}

In this subsection, we explore the measurement and properties of businesslevel capital and investment using the ASM. Our objectives are broadly threefold. First, we explore the limitations of alternative measurement methods outlined in section 12.2. In particular, we examine the properties of investment and capital measures using the modified perpetual inventory specification given in equation (2) versus the adjusted book value specification given in equation (3). We compare and contrast the properties of the micro and macro capital and investment using these alternative measurement specifications. In addition, we explore the sensitivity of analyses using such alternative capital stock measures-here our metric is the impact that alternative measures have on the measurement of total factor productivity. Second, we summarize and explore key features of the micro distribution of investment. In so doing, we highlight the features of the micro distribution that suggest an internally consistent and fully integrated micro/macro measurement of capital would be important for understanding aggregate fluctuations. Third, we explore basic aggregation issues by comparing and contrasting the properties of the distribution of investment at the establishment and at the firm level. The ASM has the advantage that analysis can be conducted at the establishment level, and it is of interest to understand how the properties of business-level investment change as we aggregate data from the establishment to the firm level.

\section{Perpetual Inventory versus Adjusted Book Values}

The ASM is the only data set that measures capital stocks and flows at the establishment level. There have, however, been some major changes in the collection of capital data on the ASM. As mentioned earlier, the ASM collected beginning- and end-of-year book values broken out by equipment and structures each year until the 1987 Census of Manufactures (CM). After 1987, the book value question is only asked during economic census years. In the 1997 CM, only total book value was collected. For these reasons, we can only construct adjusted book values of capital stocks for the period 1972-87, 1992, and 1997. Fortunately, investment data, broken out by both equipment and structures, has been collected in the ASM continuously for the entire 1972-2000 period. Using the detailed investment data along with the book value data to initialize the series, the modified perpetual inventory method described in section 12.2.2 (equation [2]) can be used to construct capital stocks at the establishment level for the vast majority of plants in the ASM.

In what follows, we often compare our measures for all plants and then 
for a subset of plants that have at least five years of prior continuous plant history. The reason for focusing on the latter subset in this context is that the difference between the capital stocks computed on an adjusted book value basis (equation [3]) and on the modified perpetual inventory basis (equation [2]) will be zero, by construction, in the year the plant first appears in the ASM and can only grow over time based upon the plant having a different vintage structure of capital relative to the average plant in its two-digit industry (see section 12.2.2 for a more complete discussion). We denote this subset of plants the "five-year continuers" in the analysis that follows.

Figure 12.5 provides a comparison of the distribution of adjusted book value capital stock and the modified perpetual inventory capital stock, using the five-year continuers. We observe that the distribution of perpetual inventory capital is slightly to the left of the adjusted book value distribution, with more mass in the center of the distribution. Thus, one difference is that the adjusted book value yields a higher mean and cross-section variance of the capital stock relative to the preferred perpetual inventory measures. However, the distributions are remarkably similar and the correlation at the micro level is above 0.9 (overall and in each year separately).

We now turn to properties of the investment rate, defined as real investment divided by the beginning of year capital stock. As figure 12.6 shows, investment rates computed using the two alternative measures of the capital stock are also highly correlated. We find that the correlation is generally higher when we include all establishments and is always greater than 0.6. This is sensible considering that the full sample includes the years when the

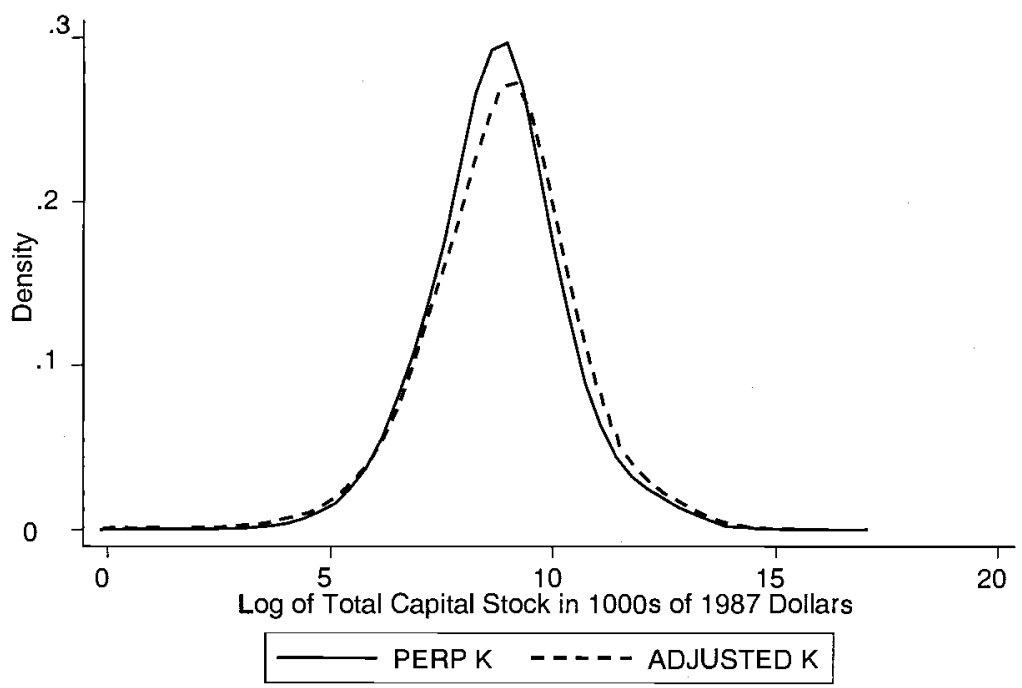

Fig. 12.5 Alternative capital measures for five-year continuers 


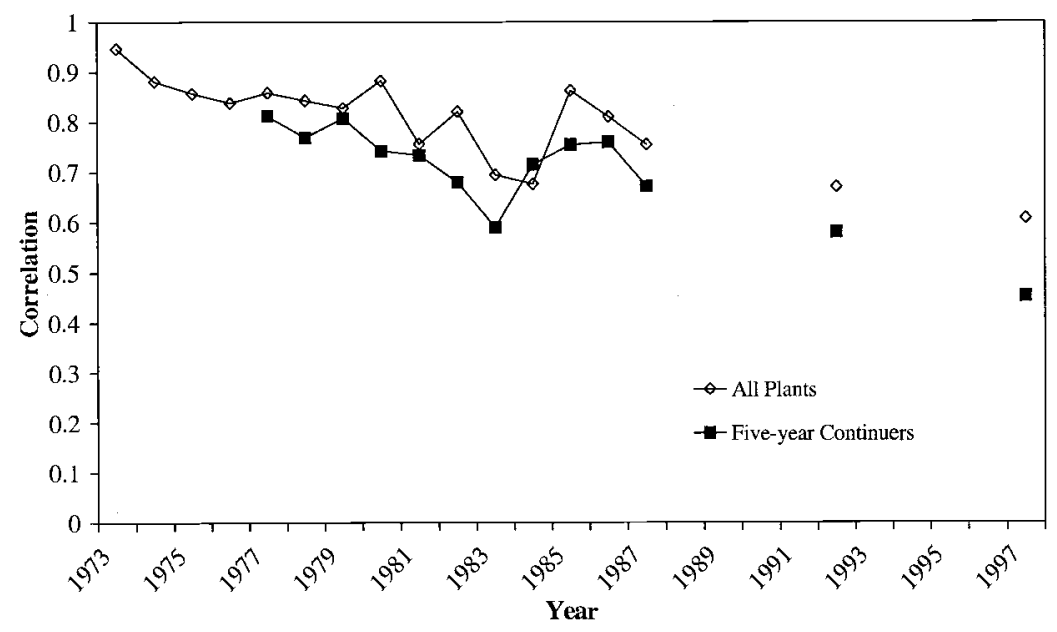

Fig. 12.6 Correlation of Adjusted and Perpetual Inventory Investment Rates

capital stocks are initialized in the perpetual inventory method (i.e., when the two measures of capital stocks are equal). When we only look at the five-year continuers, we find that the correlation of the two measures is not as strong, but is still relatively high (in the 0.6 to 0.8 range) in the period prior to 1987 when the ASM still collected data on capital stocks. In 1992 and 1997 the correlation falls off, but this also would include a set of longlived establishments that would have significantly different measures of capital stocks across the two measures.

While these correlations are quite high they are far from one, and they are also time varying. These findings thus serve as a caution to the microdata analyst who is studying investment rate behavior with microdata and only can construct capital stocks using an adjusted book value. Put differently, while the capital stock distributions are very similar, the investment rate distributions are apparently less so. In what follows, we further explore some of the key features of these distributions. For the remainder of the analysis, we focus our attention on the five-year continuers, since they are the more interesting comparison for this purpose.

In figure 12.7, we show the annual time series fluctuations for the median investment rate using the alternative two capital measures. First, we note that the perpetual inventory method yields higher medians. On the low side, the median investment rate ranges from 5.5 percent of capital in the previous period to just over 9 percent. The two measures yield the same time series variation, with both series showing increases in median investment rates during the boom periods of the business cycle, and declines during recessionary periods. The median investment rate also exhibits little if any secular trend.

In addition to examining the fluctuations in the median of the micro dis- 


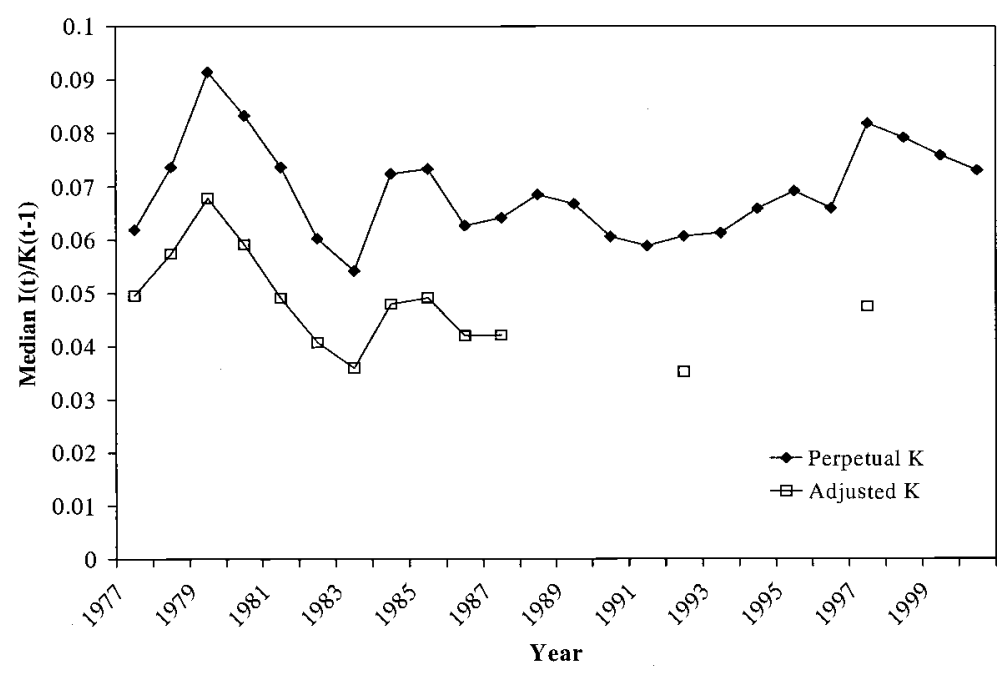

Fig. 12.7 Median $I(t) / K(t-1)$ for five-year continuers

tributions, we also examine how the shape of the distribution is changing over time. In figure 12.8, we show the interquartile range for the investment rate distributions. Interestingly, we find that the interquartile range widens during boom periods and declines during contractionary ones. If we focus on the boom in the late 1970s, we find that the 75th percentile invests roughly 16 percent more of its capital stock than the 25 th percentile did. This difference is large given that the median investment rate is roughly 9 percent at this time.

We also look at how the upper tail of the distribution fluctuates over time. In figure 12.9, we look at the difference between the median establishment investment rate and the investment rate of the 90th percentile. The right tail is more spread out using the perpetual inventory-based measure compared to the adjusted book value. We also find that the upper tail of the distribution spreads out in cyclical upturns, and this pattern holds for both capital measures. For example, in 1978 (a boom year), the 90th percentile of the establishment distribution invests nearly 28 percent more than does the median establishment, while during the recession of the early 1980 s, there is a large decline in the $90-50$ differential to about 18 percent. Looking at figure 12.7, the change in the median investment rate from peak to trough over this period is roughly 3.5 percent, while the change in the 90 50 differential is about three times that large. Since the changes in the median are relatively modest, it must be the case that this wide swing over the business cycle is caused by firms in the upper tail of the investment rate distribution.

Another dimension over which to check the respective merits of the alternative capital stock measures is to consider the aggregate behavior of 


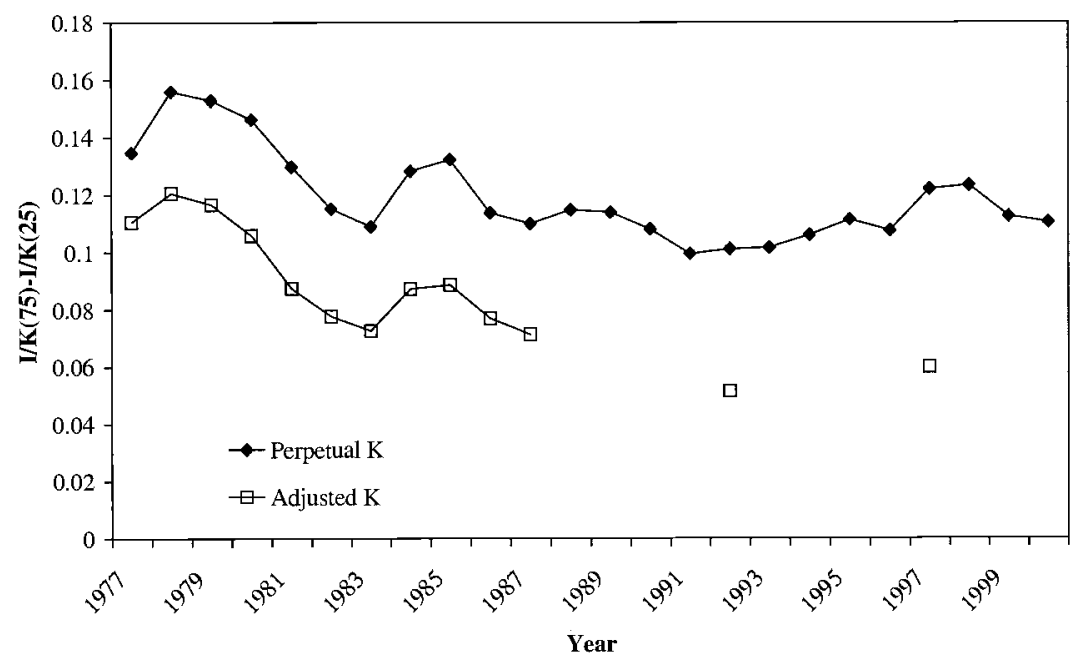

Fig. 12.8 Interquartile range of $I(t) / K(t-1)$

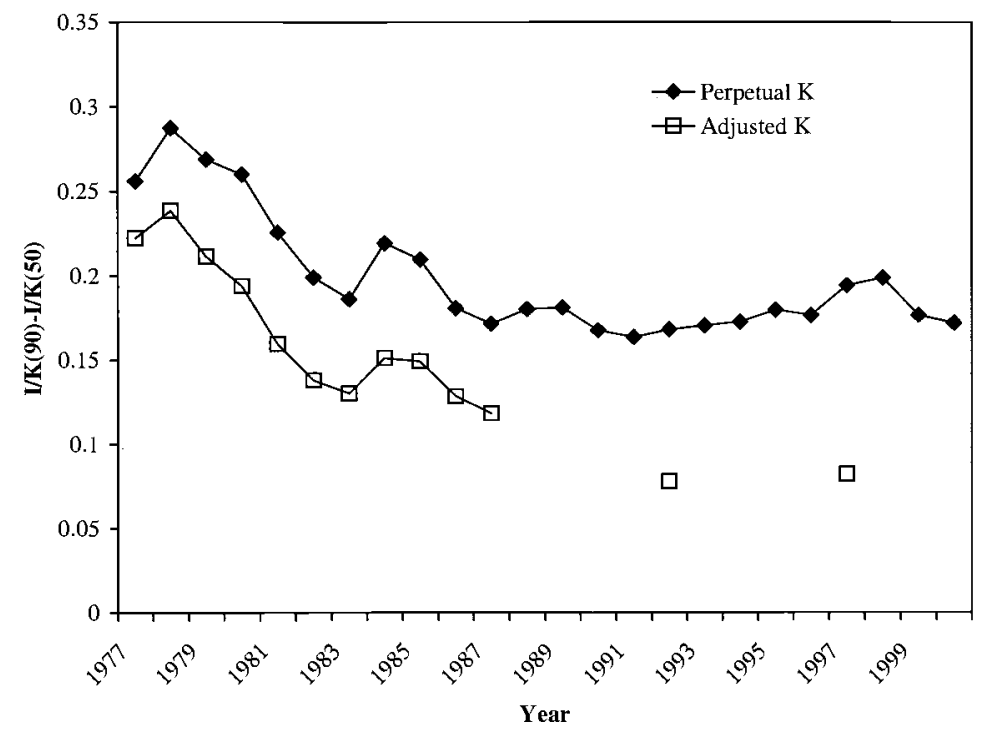

Fig. $12.9 \quad 90-50$ differential for $I(t) / K(t-1)$

the measures at the industry and total manufacturing level. For this purpose, we consider the sample of five-year continuers and generate capital stock and flow (investment) aggregates using ASM sample weights. Figure 12.10 shows the implied aggregate investment rates using this aggregation compared to the aggregate investment rate from the NBER/CES/FRB productivity database. While the latter is based on the ASM data, the capital 


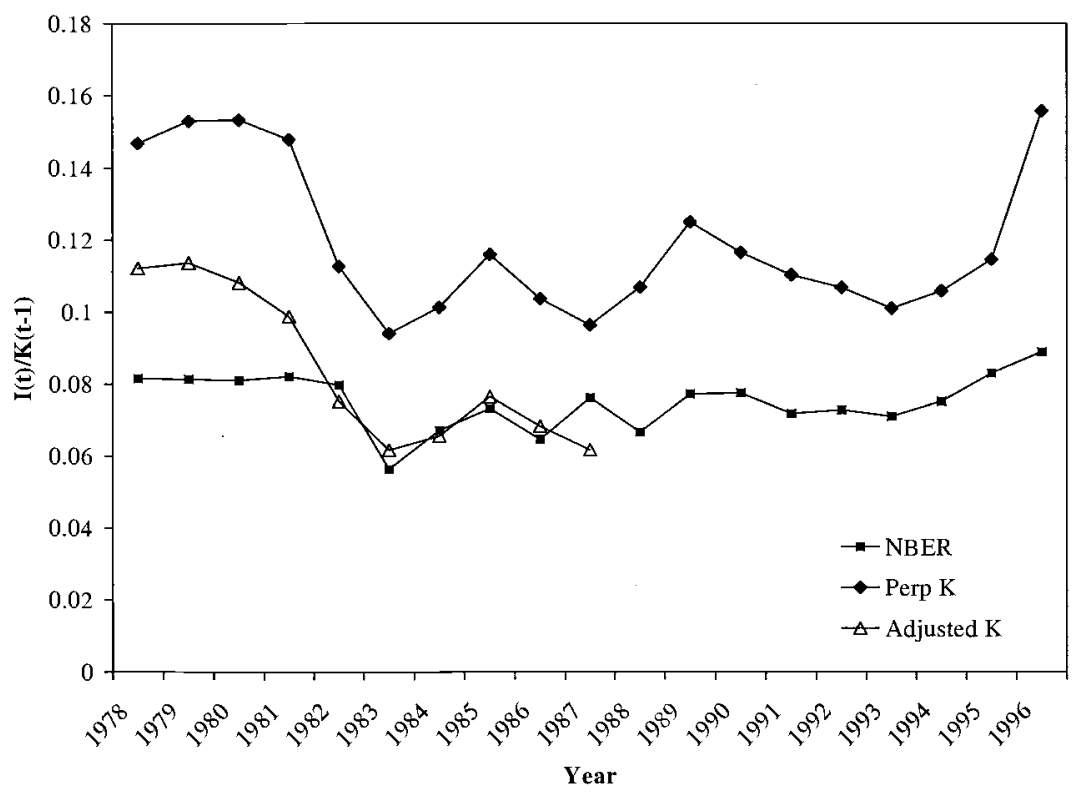

Fig. 12.10 Manufacturing $I(t) / K(t-1)$

stock series is generated using a long time series of real gross investment rates and perpetual inventory methods. ${ }^{25}$ The perpetual inventory microdata yield a higher average aggregate investment rate than either the NBER or the micro adjusted rate. Both of the total manufacturing aggregates from the microdata are highly correlated with the NBER series $(0.76$ for the perpetual inventory and 0.75 for the adjusted book value). Figure 12.11 presents the annual average of the pairwise correlations across the four-digit industry investment rates using the four-digit aggregate from the microdata and the NBER rate. For the perpetual inventory-based method the correlation averages 0.53 , while for the adjusted book value method the correlation averages 0.42 .

As an additional check of the sensitivity of micro patterns to these alternative capital stock measures, we consider how the alternative capital stock measures compare in terms of estimating production functions and measuring total factor productivity. Table 12.5 presents ordinary least squares (OLS) estimates of production functions using the alternative measures. ${ }^{26}$ It is apparent that both capital stock measures yield very sim-

25. While perpetual inventory with a long time series is used in the NBER/CES/FRB data set, the investment series is from the ASM and thus is not based upon a top-down, supply-side approach.

26. The micro sample used for these regressions is the same sample used to produce the fiveyear continuer statistics on investment rates described in this section. In particular, the sample is five-year continuers over the period 1977 to 1987 and 1992 and 1997. 


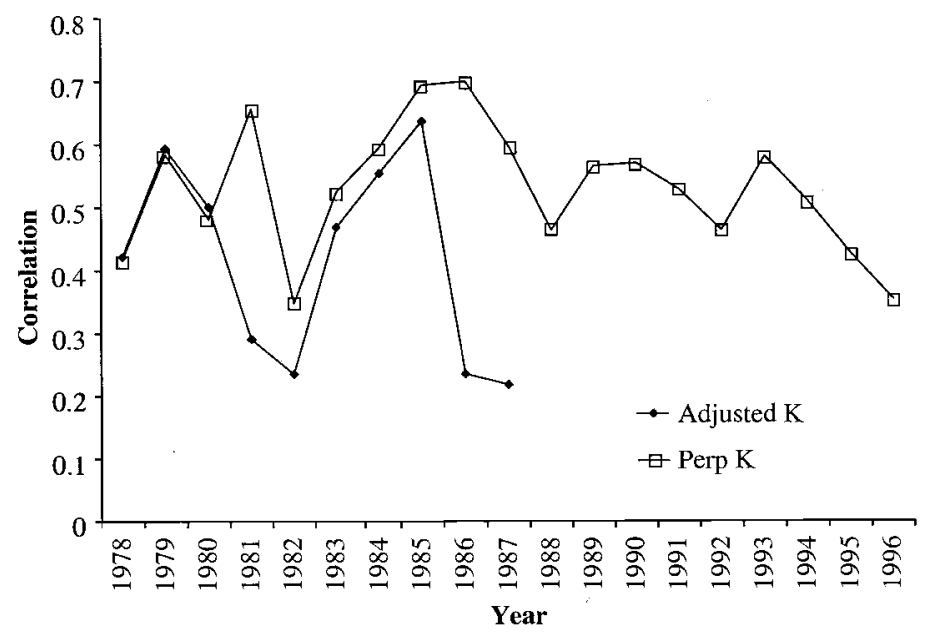

Fig. 12.11 Correlation across aggregate industry $I / K$

Table 12.5 Sensitivity of production function estimation to alternative capital measurement

\begin{tabular}{lcc}
\hline Production function estimation & Perpetual inventory & Adjusted book values \\
\hline Equipment & $0.037(0.0070)$ & $0.023(0.0006)$ \\
Structures & $0.062(0.0009)$ & $0.076(0.0008)$ \\
Labor & $0.287(0.0008)$ & $0.284(0.0008)$ \\
Material & $0.593(0.0007)$ & $0.597(0.0007)$ \\
Energy & $0.016(0.0007)$ & $0.012(0.0008)$ \\
Correlation of TFP & 0.994 & \\
Correlation of TFP (cost shares) & 0.995 & \\
\hline
\end{tabular}

Notes: Sample consists of five-year continuers in the ASM/CM for the period 1977-87 and including the years 1992 and 1997 as well. Note that book value data on K are only collected in Census years after 1987. TFP $=$ total factor productivity.

ilar results in terms of factor elasticities. While OLS estimates have limitations (e.g., endogeneity bias) so that the factor elasticities should be treated with appropriate caution, it is instructive that the alternative measures yield very similar estimates. Moreover, the correlation of the implied total factor productivity (TFP; the residual) is very high. As a related crosscheck, we calculated TFP using cost shares but again with the alternative capital stock series. Again, the correlation of TFP is very high using these alternative capital stock measures.

To sum up, the adjusted book value and perpetual inventory capital stocks are highly correlated at the micro level. They perform about the same if the use of the capital stocks is to estimate production functions and TFP. Moreover, their aggregate properties are similar and match fairly well 
and yield aggregate fluctuations at the industry and total manufacturing level similar to those from published aggregates for the manufacturing sector. There are enough differences between them that there are some notable differences in the mean and dispersion of the capital stocks, which translate into differences in the mean and dispersion of investment rates. Fortunately, these latter differences, while notable, are fairly stable over time. These patterns are reassuring for analysts who are restricted to use microdata sets where the only measure of capital available is the book value.

\section{Key Properties of Micro Distribution}

The previous section focused on the sensitivity of the distribution of capital and investment rates at the micro level to alternative measures of the capital stock. In this section, we focus on key properties of the micro distribution that are not present in the aggregate data and in turn are likely to be important for both micro studies of investment but also for our understanding of the aggregate dynamics of capital stocks and flows. In particular, in this section, we focus on the lumpy nature of investment as well as the related tremendous dispersion of investment rates at the plant level. From the previous section one could believe that all establishments invest each year, and that in some years their investment is high relative to their capital stock and other years it is low relative to their capital stock. As we will show in this section, this is hardly the case.

In figure 12.12 we show the fraction of establishments that report zero investment in each year, broken out by total investment, equipment, and structures. We look at all establishments and the five-year continuers. The two series track each other quite well, but in nearly every case five-year continuers have a smaller share of plants with zero investment. Establishments are much more likely to have zero investment in structures. The share of establishments with zero investment in structures is as high as 62 percent in 1974 , and as low as 38 percent in 1997. The fraction of establishments with zero total investment varies quite a bit, from nearly 28 percent of all establishments in 1973 to a low of 9 percent in 2000. It is also interesting to note the time series pattern in the data. The share of establishments with zero investment shows a secular decline over time, but also is countercyclical (e.g., the correlation between the median investment rate and the fraction of plants with zeroes among the five-year continuers is -0.25 ). The secular trend is somewhat weaker for the five-year continuers. We don't have a ready explanation for the declining fraction of zeroes, but taken at face value the results suggest less inertia in capital adjustment over time. It may be that capital adjustment costs have been reduced (part of this might reflect improved functioning of capital markets) or perhaps there have been secular shifts in the asset mix toward shorter-lived equipment such as computers.

At the other end of the distribution, we are interested in investments 


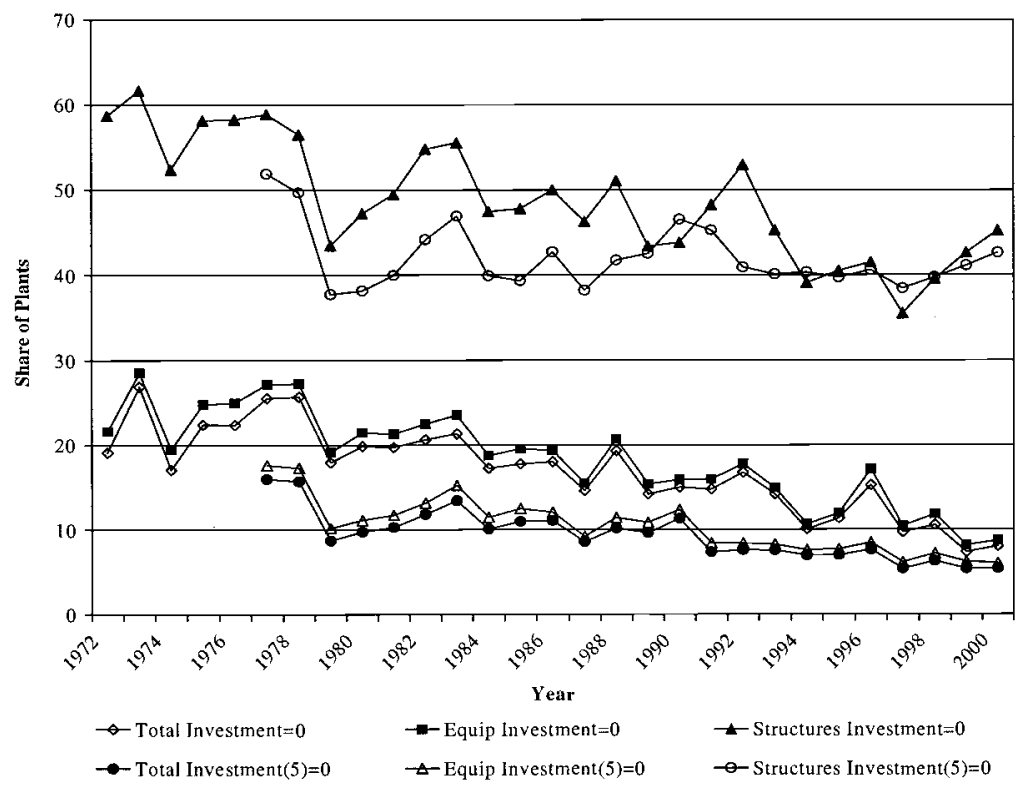

Fig. 12.12 Fraction of plants with zero investment

spikes, defined here as investment that equals more than 20 percent of the capital stock. Figure 12.13 show that spikes are highly procyclical (e.g., the correlation between the median investment rate and share of plants with an equipment spike is 0.48 for the five-year continuers). Spikes occur much more commonly in equipment investment than they do with structures. Spikes in structures decline in frequency during this time period, but spikes in equipment occur as often in the early 1970s as they do in 2000. As we saw before, five-year continuers are less likely to have zero investment. They are also more likely to have investment spikes. During recessionary periods we still observe roughly 15 percent of all establishments investing over 20 percent of the value of their entire capital stock.

As evidenced by the large fraction of zeros and the large fraction of investment spikes, it is clear that investment at the establishment level is quite lumpy. In order to quantify this in more detail, we construct the share of cumulative investment that is due to the largest year for two samples of establishments: five-year continuers and a panel of long-lived establishments that have been in the ASM from 1972 to 2000 continuously. The results of this exercise are reported in table 12.6. For the group of five-year continuers in each year, we find that (on average across all years from 1977 to 2000) the largest year of investment over any given five-year period accounts for over 40 percent of investment in terms of both total investment and invest- 


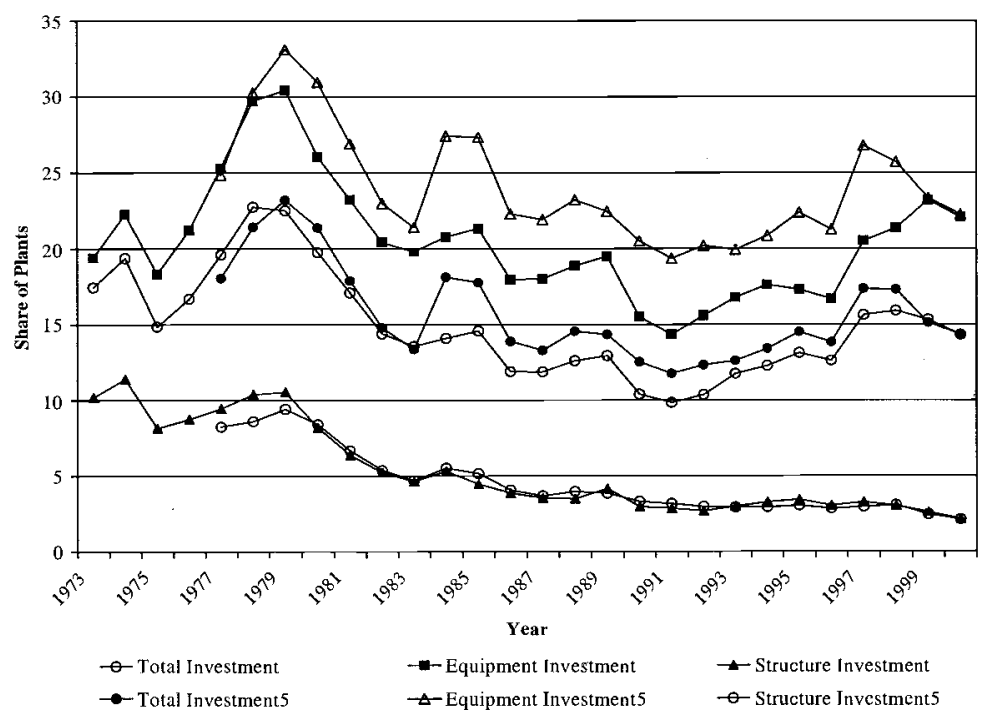

Fig. 12.13 Investment spikes: $I(t) / K(t-1)>.2$

ment in equipment. ${ }^{27}$ In general, these two numbers have been monotonically decreasing over time, from the 47 percent range in the mid-1970s to roughly 39 percent in 2000 . A similar pattern shows up in the data for structures, but on average the largest year of structures investments accounts for a much larger fraction of cumulative investment for the five-year continuers, over 60 percent in the average year, and the decline in the average is much less pronounced than in the total and equipment investment.

Looking at our panel of long-lived establishments we see that roughly 17 percent of their total investment in the past thirty years comes in just one year, and the three-year total is roughly twice that or 32 percent. At least 5 percent of investment comes from the largest year of investment, and in some cases all investment comes in one year. While the results are quite similar for equipment, the results for structures are even more striking. On average, 32 percent of structures investment comes from the largest year of investment, and the largest three-year average is nearly 60 percent of the cumulative investment in structures. At least 16 percent of cumulative investment in structures at these establishments comes from the largest single year of investment.

The findings on lumpy investment indicate that understanding investment dynamics at the micro level requires understanding both the intensive

27. This exercise is closely related to the much more detailed and more sophisticated analyses of investment spikes in Doms and Dunne (1998) and Cooper, Haltiwanger, and Power (1999). 
Share of cumulative investment

\begin{tabular}{|c|c|c|c|c|}
\hline Time period & Variable & Mean & Min. & Max. \\
\hline Last five years & $\begin{array}{l}\text { The largest total investment/cumulative total } \\
\text { investment }^{\text {a }}\end{array}$ & .414 & .389 & .475 \\
\hline Last five years & $\begin{array}{l}\text { The largest equipment investment/cumulative } \\
\text { equipment investment }{ }^{\mathrm{a}}\end{array}$ & .414 & .391 & .467 \\
\hline Last five years & $\begin{array}{l}\text { The largest structures investment/cumulative } \\
\text { structures investment }{ }^{\mathrm{a}}\end{array}$ & .627 & .608 & .675 \\
\hline Twenty-nine years & $\begin{array}{l}\text { The largest total investment/cumulative total } \\
\text { investment }^{\text {b }}\end{array}$ & .169 & .056 & 1 \\
\hline Twenty-nine years & $\begin{array}{l}\text { The largest equipment investment/cumulative } \\
\text { equipment investment } \mathrm{t}^{\mathrm{b}}\end{array}$ & .167 & .053 & 1 \\
\hline Twenty-nine years & $\begin{array}{l}\text { The largest structures investment/cumulative } \\
\text { structures investment }^{\mathrm{b}}\end{array}$ & .325 & .064 & 1 \\
\hline Twenty-nine years & $\begin{array}{l}\text { The largest three years of total investment/ } \\
\text { cumulative total investment }{ }^{\mathrm{b}}\end{array}$ & .362 & .162 & 1 \\
\hline Twenty-nine years & $\begin{array}{l}\text { The largest three years of equipment investment/ } \\
\text { cumulative equipment investment } \mathrm{t}^{\mathrm{b}}\end{array}$ & .362 & .157 & 1 \\
\hline Twenty-nine years & $\begin{array}{l}\text { The largest three years of structures investment/ } \\
\text { cumulative structures investment }{ }^{\mathrm{b}}\end{array}$ & .594 & .171 & 1 \\
\hline
\end{tabular}

aDistribution across all years 1977-2000 for five-year continuers.

${ }^{b}$ Distribution across all establishments in the 29-year balance panel with approximately 6,600 observations.

(how much investment) and the extensive (invest or not invest) margins. The finding that the extensive margin and relatedly the fraction of spikes are so procyclical, suggests that understanding the procyclicality of investment at the micro level requires understanding the forces that cause plants to change from inaction to action. As has been highlighted in the recent theoretical and empirical literature, the models that can account for these dynamics are models where there is some type of nonconvexity in capital and other adjustment costs. The latter models inherently have a range of inaction and also have the interesting feature that aggregate dynamics depend critically on the entire distribution of micro behavior because it is critical to know how many plants are close to their extensive margin thresholds to understand how aggregate behavior responds to aggregate shocks.

We now turn to another key property of the micro distribution of investment. As is evident from the characterization of the distribution of investment in the prior section, there is substantial dispersion in investment rates across businesses. There are a large fraction of zeros and a large fraction of spikes. Those with zero investment are, given depreciation, experiencing a decline in their capital stock. Those with spikes are, even taking into account depreciation, experiencing large increases in their capital stock. Thus, one inference that immediately emerges from the distribution of investment rates is that there are considerable changes in the allocation 
of capital across establishments all the time. In addition, what is not evident in the results presented thus far is that another potentially important source of capital reallocation is the entry and exit of establishments. Entry and exit rates in U.S. manufacturing are not as large as they are in other sectors, but still it is of interest to consider the role of entry and exit in the reallocation of capital across establishments. A related issue that we explore in more depth in the next section is that the exit of establishments (or firms) may not be properly accounted for in the measurement of depreciation used to build aggregate capital stocks. That is, the standard measurement of depreciation is based upon the service life of an asset. The latter does not explicitly consider whether the exit of a firm or establishment changes the useful service life of an asset. Instead, efficiency or depreciation schedules implicitly assume that the capital from an exiting business is still in useput differently, it is implicitly assumed that the capital from an exiting business is transferred to another business (presumably through the secondary market for capital).

To explore these issues, we use the (perpetual inventory-based) capital stock measures for the ASM from 1972 to 1998, along with longitudinal identifier links created by Davis, Haltiwanger, and Schuh (1996), extended by Haltiwanger and Krizan (1999) and Foster, Haltiwanger, and Kim (2005), as well as longitudinal identifiers from the Longitudinal Business Database (LBD) created from the BR (Jarmin and Miranda 2002). These identifiers permit us to take any pair of consecutive years and classify plants as being entrants, exits, or continuers.

Using this classification, we compute the growth rate of the capital stock at each plant as

$$
g k_{e t}=\frac{K_{e t}-K_{e t-1}}{X_{e t}} \text { where } X_{e t}=.5 \cdot\left(K_{e t}+K_{e t-1}\right),
$$

where $K_{e t}$ is the real capital stock for establishment $e$ at time $t$. For this purpose, we used the real capital stocks computed using the modified perpetual inventory method, and since we are interested in entry and exit we use all plants. ${ }^{28}$ This growth rate measure mimics the growth rate measure used in the job creation and destruction literature (see Davis, Haltiwanger, and Schuh 1996). It has the desirable feature that it is symmetric like a log first difference (indeed, it can be shown that this is a second-order approximation to a $\log$ first difference), but unlike the log first difference it incorporates establishment entry and exit. Using this growth rate measure, aggregate gross capital creation and destruction measures are defined respectively as

28. Note that our neglect of retirement/sales implies that we are potentially missing an important part of the gross capital destruction for continuing establishments. Caballero, Engel, and Haltiwanger (1995) find that the average gross investment rate (not net investment rate) for businesses with negative gross real investment is around 3 percent. We are missing that three percent in this analysis in part although it may be partly captured in the depreciation rates we are using. See Caballero, Engel, and Haltiwanger (1995) for further discussion. 


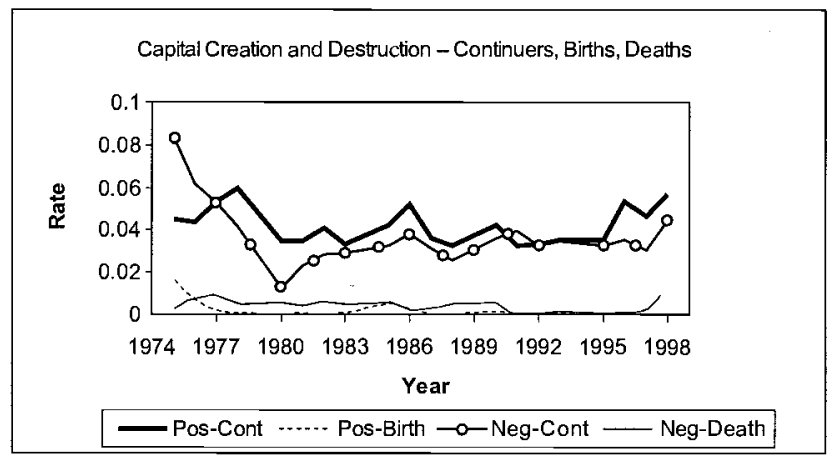

Fig. 12.14 Capital creation and destruction: Continuers, births, deaths

$$
\begin{gathered}
\operatorname{POS} K_{e t}=\sum_{g k_{e t} \geq 0} \frac{X_{e t}}{X_{t}} g k_{e t} \\
\mathrm{NEG} K_{e t}=\sum_{g k_{e t}<0} \frac{X_{e t}}{X_{t}}\left|g k_{e t}\right|
\end{gathered}
$$

Using these measures, note that by definition the aggregate net capital stock growth rate is equal to $\mathrm{POS} K_{e t}-\mathrm{NEG} K_{e t}$.

Figure 12.14 depicts the capital creation and destruction rates from the mid-1970s to the late 1990s for equipment investment. ${ }^{29}$ The net growth rate in capital is on average much smaller than the gross capital creation and destruction rates calculated in this manner. Not surprisingly, gross capital creation is procyclical and gross capital destruction is countercyclical. However, the cyclical patterns vary considerably across cycles. In the late 1970s, those businesses that were exiting and/or had very low gross investment (so the net capital stock was falling) decreased their capital destruction, and this led to a rise in the net capital stock. In contrast, the booms of the 1980s and 1990s were driven more by entrants and/or businesses whose gross investment was considerably larger than depreciation so that their net capital stocks grew substantially. One way of viewing these findings is that they illustrate that the changes in the aggregate capital stock in the manufacturing level at cyclical frequencies varies in terms of what part of the micro distribution is changing. It is also interesting to note that, like net job creation in manufacturing, net capital growth in manufacturing is driven more by fluctuations in capital destruction than by cap-

29. We exclude the first year of each ASM panel (1974, 1979, 1984, 1989, and 1994) since the ASM does not have a representative sample of entrants and exits in those years. This is somewhat unfortunate since many of these years (1974 excluded) are boom years, so we miss some of the story on what happens during booms. This also yields the average net growth to be considerably lower than it would be if these years were included. Note that we use all plants in the ASM that are identified to be either an entrant, an exit, or a continuer and we also use sample weights. 
ital creation. The standard deviation of capital destruction is 1.5 times the standard deviation of capital creation (although this appears to be driven primarily by the cyclical variation in the 1970s and early 1980s).

An interesting question here is the role of entry and exit. Figure 12.14 shows the components of gross capital creation accounted for by continuers (businesses that are present in year $t-1$ and $t$ ) and entrants (businesses not present in period $t-1$ but present in period $t$ ) as well as the components of gross capital destruction accounted for by continuers and exits (businesses present in year $t-1$ but not present in year $t$ ). Figure 12.14 shows that the contribution of entry and exit is quite modest in this setting although the share of capital creation accounted for by entry and the share of capital destruction accounted for by exit both exceed 20 percent in specific years. Part of the reason that the contribution of entry and exit is modest in this case is that as a share of the capital stock in any given year, entering and exiting plants account for a very small share (less than 1 percent each). This is because entering and exiting plants tend to be younger and smaller plants. However, the latter suggests that these annual calculations may be somewhat misleading regarding the contribution of entry and exit. As we will explore in the next section, the investment rates of young businesses (e.g., less than ten years old) are very high so the cumulative contribution of entry taking into account the immediate post-entry growth is substantially higher. Still, it is striking that figure 12.14 shows that most of the fluctuations in gross capital creation and destruction rates in manufacturing are from continuers. For example, the large decline in capital destruction during the boom in the late 1970s is entirely driven by a decline in capital destruction by continuers. The role of entry and exit in nonmanufacturing may be much larger, as we will see in the next section, since the entry and exit rates are much larger in nonmanufacturing. To sum up our plant-level evidence on the properties of the micro distributions, we emphasize two key points. First, the micro distribution of investment is very lumpy, and second, the micro distribution is very heterogeneous, with some businesses rapidly expanding their capital stocks through large gross investments and others contracting their capital stocks either by depreciation or exit.

\section{Firm versus Establishment Micro Properties}

As the only data set that collects measures of investment and capital at the establishment level, the ASM is a unique data set that permits exploration of the differences between establishment data and data aggregated to the firm level. In this section, we summarize the findings from an investigation of the comparison between establishment and firm effects but for the sake of brevity do not include the underlying tables and figures (available on request). For this analysis, we restrict our attention to those plants that are classified as five-year continuers. The median of the firm distribu- 
tion exhibits that same overall time series pattern as the establishment-level data, but with the median firm investment rate being slightly higher than the establishment investment rate. The correlation of our two measures of capital, perpetual inventory and adjusted book value, show that the two measures are also highly correlated at the firm level, ranging from 0.6 to 0.8 and exhibiting a slight trend upward during this period. The correlation at the firm level is slightly lower than at the establishment level, and the series shows less variation over time. The interquartile range and 90-50 difference show exactly the same time series patterns and are roughly identical in terms of levels. In terms of the micro properties of the firm series, the fraction of firms with zero investment is somewhat lower for equipment and total investment, but the fraction of firms with zero investment in structures is significantly lower than the fraction of establishments with zero investment. Investment spikes in structures exhibit the same patterns and levels at the firm and establishment level, but the incidence of spikes in equipment and total investment are much lower for firms than for establishments. These last two points suggest that firm investment is somewhat less lumpy than plant investment, smoothing structures investment across the firm but concentrating investment at particular plants within the firm. Equipment and total investment also exhibit smoother investment patterns, with slightly fewer zero-investment firms and fewer investment spikes. While the results for the ASM establishment versus firm level are roughly equivalent, some differences do exist. In the following section, we describe the micro properties of another firm-level data set, the ACES. ${ }^{30}$

\subsubsection{Investment Dynamics at the Micro Level for the Entire Economy}

In this section, we look at patterns of investment across firms in all sectors of the economy (not just manufacturing as in the preceding section). For this purpose we use the ACES data on gross investment at the firm level along with the book value information. ${ }^{31}$ The ACES is now the primary source of data on business investment in the U.S. statistical system. To date, however, it has been used sparingly by researchers looking at invest-

30. For the analysis reported here we are using the distributions across plants versus the distributions across firms without weighting by some measure of activity (in this case the most appropriate weight would probably be capital). It turns out that most firms are single units (i.e., have one plant) so the micro distributions of firms and plants are quite similar. However, multi-unit plant firms account for a large fraction of activity. Thus, it would be interesting to explore the activity-weighted distributions. Put differently, it would be interesting to focus some attention on the large, complex multi-units who have many establishments. The behavior of the latter at the firm level is likely to look quite different from the plant-level data.

31. We have not constructed real investment flows and capital stocks with the ACES data. Many large firms in the ACES span many industries, which somewhat complicates the choice of appropriate deflators for constructing real values for investment flows and capital stocks. Most of the calculations using ACES in this paper are within year. In addition, we don't construct perpetual inventory capital stocks using ACES. Therefore, deflating ACES investment and capital stocks was not a high priority for this paper. 
ment dynamics. This is partly due to its relatively recent introduction and to researchers' unfamiliarity with the survey. We hope to shed light on the usefulness of the ACES for understanding investment dynamics and to suggest ways the survey can be changed to improve its utility in this area. Before moving on to this analysis, it is useful to briefly compare the ACES to the ASM on some key measures.

\section{Comparing the ACES and ASM}

Differences in the sampling units and survey design make comparisons between the ACES and ASM difficult. Both surveys sample larger units (firms and manufacturing establishments, respectively) with certainty. The surveys differ markedly in how they handle the noncertainty cases, however. In particular, the ASM selects a sample of smaller establishments that it follows over a five-year panel. This allows the use of the perpetual inventory methods discussed above. The ACES, on the other hand, selects a new probability sample each year. Thus, perpetual inventory methods can only be used to construct firm-level capital stocks for the largest ACES firms.

Despite the differences between the two surveys it is possible to compare various statistics computed from each. Here we focus on the investment rates and the share of firms experiencing spikes in investment. Figure 12.15 compares the median investment rate $(I / K$, computed as total capital expenditures divided by total fixed assets) and the share of businesses with investment rates exceeding 0.2 (i.e., those experiencing spikes) across ACES firms and ASM establishments. The differences in units and industry focus notwithstanding, we see that the results are broadly consistent. Firms in the ACES have slightly higher investment rates than the manufacturing establishments in the ASM, and a larger proportion of ACES firms experience investment spikes. While measurement differences could play a role (for instance, we believe the capital stock measures available for the ASM are more reliable than the book value information collected but not published on the ACES), the differences between the ACES and ASM seen in figure 12.15 may stem largely from higher investment rates in the nonmanufacturing sector over the 1990s. All of the series trend up over the 1990s following the business cycle.

Now we turn our attention to the contribution of entry and exit and also to a closely related idea raised in the prior subsection - that is, the contribution of young businesses to investment. We focus on these issues in this context because, in the nonmanufacturing sectors, entry and exit are much more important in accounting for the reallocation of outputs and inputs and for growth (see, e.g., Foster, Haltiwanger, and Krizan 2001, 2002). As mentioned in the introduction, one of the limitations of aggregate data on capital stocks and flows is that it is difficult to capture the contribution of young versus mature businesses or the contribution of entry and exit. It is 


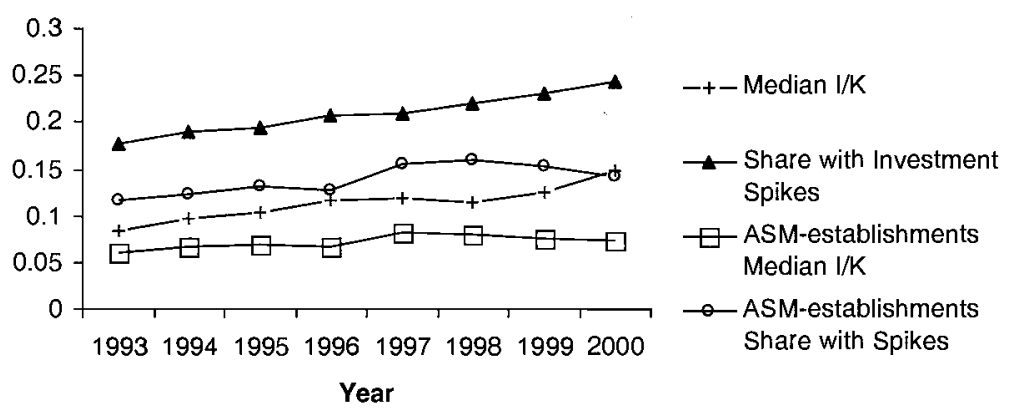

Fig. 12.15 Median investment rates and proportion of firms with spikes: ACES versus ASM

also the case that typical business surveys (including ACES) have some limitations when it comes to capturing the roles of entry and young businesses, as often the focus of these surveys is on large, mature businesses. Accordingly, the analysis in this section serves the purpose both of illustrating the importance of considering the age distribution of businesses (and entry and exit) and also of highlighting some of the limitations in trying to assess the contribution of these factors given the traditional emphasis in data collection on larger, more mature businesses. Another reason to be particularly interested in the investment behavior of young firms is that we believe they are among the first to adopt new technologies and business practices. This may have been particularly true over the period covered by the ACES: the 1990s.

\section{Incorporating Age Information into the ACES}

The ACES is not designed to provide statistics on investment by firm age. However, the ACES can be easily linked to the LBD, which contains longitudinally linked establishment-level data with firm ownership information from 1975 to the present. The LBD contains two sources of information on firm age. First, one can use the first year a firm's numeric identifier (FIRMID) is observed in the LBD. However, numeric firm identifiers in the LBD are not intended for longitudinal analysis. For example, events such as mergers and acquisitions can result in changes to numeric firm identifiers for continuing businesses. An alternative measure of firm age is the age of the oldest establishment owned by the firm. While this measure is not ideal either, it yields a much more plausible age distribution of firms than that which results from using only numeric firm identifiers. ${ }^{32}$

32. Work is currently underway at the CES to create firm-level longitudinal linkage in the LBD. Once completed, this work will allow researchers to construct more sophisticated measures of firm age. 


\section{Basic Facts about Investment and Firm Dynamics by Firm Age}

Table 12.7 provides information on the distribution of employment across the firm age distribution for 1998. The LBD contains the universe of firms with paid employees and thus provides the benchmark to compare with those employer firms covered in the ACES. The first column in the table shows the 1998 distribution of employment in the LBD. Note the mass point at age twenty-three. This results from the fact that the LBD extends back only to 1975 . Thus, all firms owning establishments born on or before 1975 have the same age. These older firms tend to be large and, therefore, account for large portion of overall economic activity.

The second and third columns of table 12.7 show the unweighted and weighted percentages of total LBD employment by age for ACES firms. The table clearly shows that young firms are undersampled in the ACES. For example, good responses for the 1998 ACES were received from firms accounting for only 1.5 percent of all employment at age 1 firms. Using ACES sample weights, these firms represent only 15 percent of age $1 \mathrm{em}-$ ployment. Recall, however, that ACES is not stratified by firm age. Coverage is much better for the more mature firms that account for a lot of economic activity. Thus, ACES is representative of total investment spending.

Figure 12.16 looks at investment rates over the age distribution. Because there are limited observations on young firms within each year, we use pooled data to construct the figure. That is, each age category (below twenty-five) is made up of observations from multiple years. ${ }^{33}$ The figure clearly shows that investment rates, measured as the ratio of total capital expenditures to fixed assets, decline with firm age. Younger firms invest much more intensively than do older firms. In addition, younger firms pursue more varied investment strategies relative to older firms, as shown in the decline of 90-10 differential in investment intensity as firms age.

An alternative way to examine investment behavior across the age distribution of firms is to follow a cohort of firms over time. This is difficult with the ACES as there is no explicit panel nature to the survey. The ACES does a good job of longitudinally tracking only larger certainty case businesses. These, of course, are mostly all old. Young firms are mostly small and are, therefore, only observed in the ACES once over the 1993-2000 period (111,446 out of 141,605 ACES-1 firms observed over the 1993-2000 period are observed only once). Thus, the only way to follow a cohort over time is to construct a synthetic cohort of firms that were all born in the same year but where the composition of the observed cohort changes over different survey years.

Table 12.8 looks at a synthetic cohort of 1993 births over the period cov-

33. Note that the oldest firms in the LBD (i.e., those born or owning establishments born before 1975) dominate the age categories from eighteen on up. 
Distribution of paid employment by firm age- 1998

\begin{tabular}{|c|c|c|c|c|c|c|}
\hline \multirow[b]{2}{*}{ Firm age } & \multirow{2}{*}{$\frac{\text { Employment }}{\text { LBD }}$} & \multicolumn{2}{|c|}{ ACES coverage } & \multicolumn{3}{|c|}{ Age share of total } \\
\hline & & $\begin{array}{c}\text { Unweighted } \\
(\%)\end{array}$ & $\begin{array}{c}\text { Weighted } \\
(\%)\end{array}$ & $\begin{array}{l}\text { LBD } \\
(\%)\end{array}$ & $\begin{array}{c}\text { ACES } \\
\text { (unweighted; \%) }\end{array}$ & $\begin{array}{c}\text { ACES } \\
\text { (weighted; \%) }\end{array}$ \\
\hline 0 & $1,452,603$ & $\mathrm{D}$ & $\mathrm{D}$ & 1.31 & $\mathrm{D}$ & $\mathrm{D}$ \\
\hline 1 & $3,146,743$ & 1.50 & 15.02 & 2.85 & 0.10 & 0.55 \\
\hline 2 & $3,193,107$ & 2.99 & 47.21 & 2.89 & 0.20 & 1.76 \\
\hline 3 & $2,711,276$ & 2.80 & 45.47 & 2.45 & 0.16 & 1.44 \\
\hline 4 & $2,551,283$ & 3.76 & 45.14 & 2.31 & 0.20 & 1.34 \\
\hline 5 & $2,377,135$ & 5.13 & 51.89 & 2.15 & 0.25 & 1.44 \\
\hline 6 & $2,553,304$ & 7.44 & 54.91 & 2.31 & 0.39 & 1.63 \\
\hline 7 & $2,315,490$ & 5.71 & 53.51 & 2.09 & 0.27 & 1.44 \\
\hline 8 & $2,006,223$ & 5.11 & 54.66 & 1.81 & 0.21 & 1.28 \\
\hline 9 & $2,174,030$ & 9.95 & 63.45 & 1.97 & 0.44 & 1.61 \\
\hline 10 & $2,263,811$ & 12.95 & 65.44 & 2.05 & 0.60 & 1.73 \\
\hline 11 & $2,584,330$ & 14.43 & 59.58 & 2.34 & 0.76 & 1.80 \\
\hline 12 & $2,671,816$ & 8.31 & 48.36 & 2.42 & 0.45 & 1.51 \\
\hline 13 & $2,296,896$ & 13.55 & 66.72 & 2.08 & 0.64 & 1.79 \\
\hline 14 & $2,078,559$ & 12.69 & 63.81 & 1.88 & 0.54 & 1.55 \\
\hline 15 & $1,648,923$ & 14.60 & 60.48 & 1.49 & 0.49 & 1.16 \\
\hline 16 & $2,376,955$ & 21.71 & 78.26 & 2.15 & 1.06 & 2.17 \\
\hline 17 & $1,558,257$ & 18.20 & 66.93 & 1.41 & 0.58 & 1.22 \\
\hline 18 & $1,386,752$ & 16.09 & 70.97 & 1.25 & 0.46 & 1.15 \\
\hline 19 & $1,410,778$ & 22.09 & 77.46 & 1.28 & 0.64 & 1.27 \\
\hline 20 & $1,376,125$ & 18.92 & 69.44 & 1.24 & 0.53 & 1.11 \\
\hline 21 & $2,453,113$ & 39.00 & 84.61 & 2.22 & 1.96 & 2.42 \\
\hline 22 & $2,019,449$ & 65.59 & 154.43 & 1.83 & 2.71 & 3.64 \\
\hline 23 & $59,953,493$ & 70.43 & 92.98 & 54.23 & 86.38 & 65.00 \\
\hline Total & $110,560,451$ & 44.21 & 77.57 & & & \\
\hline
\end{tabular}

Notes: $\mathrm{LBD}=$ Longitudinal Business Database. $\mathrm{D}$ indicates that the statistic is suppressed in order to avoid disclosing data for individual companies.

ered by the ACES. The first four columns of the table highlight the small share of total activity accounted for by any given birth cohort (the payroll and employment shares in the first two columns are based on universe information from the LBD). It is interesting to note that young firms account for a smaller share of investment and assets than they do payroll and employment. This is true even though they invest more intensively than do more mature firms.

The behavior of investment intensities for this synthetic cohort is not as clean as that depicted in figure 12.16. Within a year, we generally find that the mean and median investment intensities are higher for younger firms. Figure 12.16 essentially pools statistics across time and shows the downward trend in investment intensity as firms age. However, since the ACES does not track individual young firms over an extended period of time, it's 


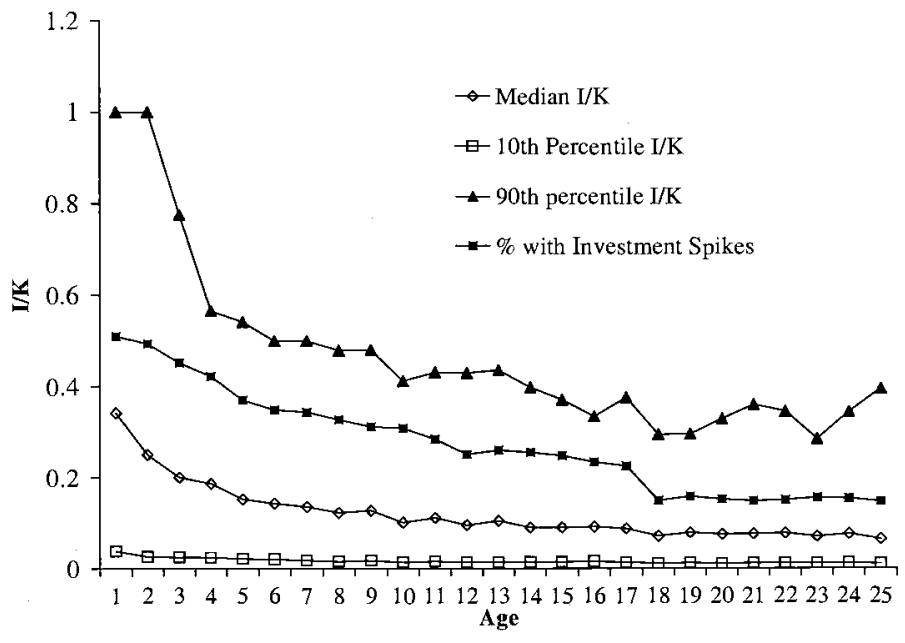

Fig. 12.16 Firm age distribution of $I / K$ (ACES-1 firms)

Table 12.8

Share of activity for the 1993 birth cohort (\%)

\begin{tabular}{cccccccc}
\hline Year & $\begin{array}{c}\text { Share of } \\
\text { payroll }\end{array}$ & $\begin{array}{c}\text { Share of } \\
\text { employment }\end{array}$ & $\begin{array}{c}\text { Share of } \\
\text { investment }\end{array}$ & $\begin{array}{c}\text { Share of } \\
\text { capital }\end{array}$ & $\begin{array}{c}\text { Relative } \\
\text { share of } \\
\text { investment }\end{array}$ & $\begin{array}{c}\text { Relative } \\
\text { share of } \\
\text { capital }\end{array}$ & $\begin{array}{c}\text { Median of } \\
\text { investment/ } \\
\text { capital }\end{array}$ \\
\hline 1993 & 1.38 & 1.12 & D & D & D & D & D \\
1994 & 2.04 & 3.02 & 0.48 & 0.30 & 15.89 & 9.93 & 19.63 \\
1995 & 1.93 & 2.79 & 1.13 & 0.86 & 40.50 & 30.82 & 18.54 \\
1996 & 1.82 & 2.58 & 1.10 & 0.80 & 42.64 & 31.01 & 20.57 \\
1997 & 1.64 & 2.36 & 1.18 & 0.62 & 50.00 & 26.10 & 25.00 \\
1998 & 1.72 & 2.15 & 1.35 & 0.53 & 62.79 & 24.65 & 16.36 \\
1999 & 1.74 & 2.06 & 0.71 & 0.59 & 34.47 & 28.64 & 14.89 \\
2000 & 1.12 & 1.97 & 0.73 & 0.57 & 37.06 & 28.93 & 19.08 \\
\hline
\end{tabular}

Note: D indicates that the statistic is suppressed in order to avoid disclosing data for individual companies.

difficult to make inferences about the behavior of a given cohort since the composition of the sample changes from year to year. Obviously, the sample in out years would only contain successful entrants, which most likely invested more intensively than did the unsuccessful ones that were in the sample in previous periods. This may explain why we don't see the same patterns for a synthetic cohort as we do across the age distribution within a given year.

Another reason to be interested in understanding the investment behavior of young firms is that they may chose a different mix of capital than more mature firms. New firms are often more likely to experiment with new 


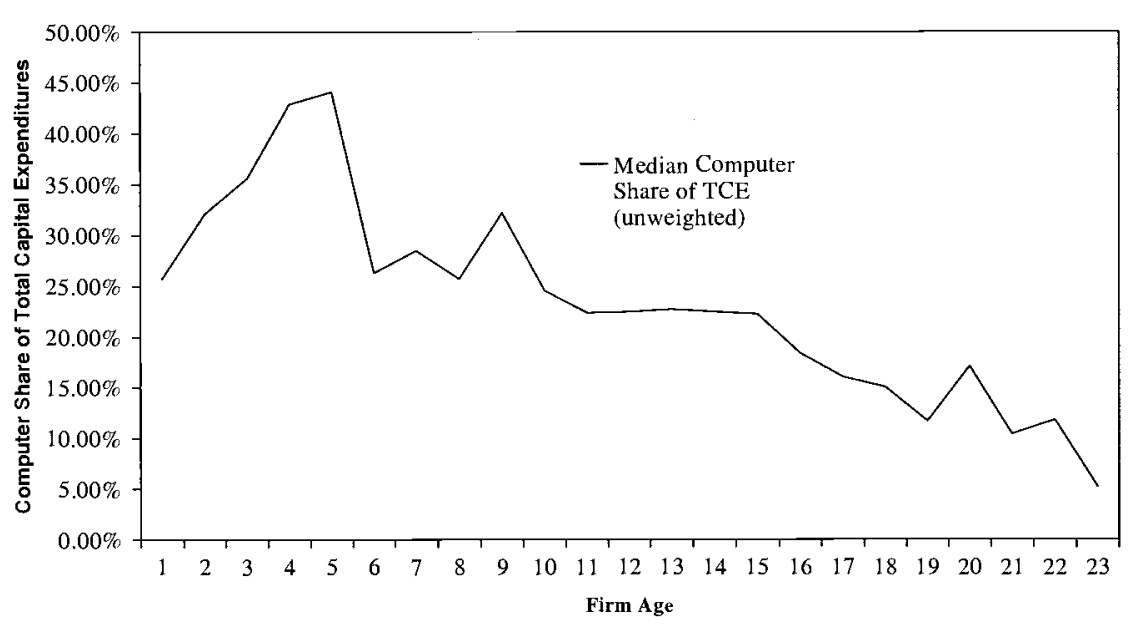

Fig. 12.17 Median computer share of TCE (unweighted): 1998

technologies. Figure 12.17 looks at this issue by comparing the share of total capital expenditure accounted for by IT equipment in 1998 across the firm age distribution. Here we see that older firms devote a smaller share of their investment budgets to IT equipment. This is admittedly a very limited analysis. The small number of observations in the ACES for younger firms limits our ability to control for other factors such as industry and size and we only have one year with detailed asset information. ${ }^{34}$ Nevertheless, figure 12.17 demonstrates that asset mix is a function of firm age.

We compare the share of different measures of economic activity at young firms across the 1990s in table 12.9. The table shows that the share of employment accounted by firms less than four years old is roughly constant, over the 1990s, at just under 10 percent. The contribution of young firms to net employment growth is much larger as most age cohorts usually experience reductions in employment.

The striking feature of table 12.9 is the low share of total investment accounted for by young firms. These firms account for nearly 10 percent of total employment (at firms with paid employees) yet only account for, on average, 3 percent of total investment. New firms seem to enter the ACES with some lag. For instance, the ACES has very limited coverage of age 0 and 1 firms. It is possible that if we imputed missing ACES investment for age 0 and 1 firms in 1997 and 1998, we would see more investment by younger firms in these years as well.

34. That is, at the time of this research, data on investment by detailed asset type were only available for 1998. Such data have since been released for 2003, but too late for inclusion herein. See Wilson (2004) for more details regarding the asset mix of firms using the 1998 ACES microdata. 
Table 12.9

Share of activity at young firms over the 1990s (\%)

\begin{tabular}{|c|c|c|c|c|c|c|c|c|}
\hline Firm age & 1993 & 1994 & 1995 & 1996 & 1997 & 1998 & 1999 & 2000 \\
\hline \multicolumn{9}{|c|}{ Share of total ACES-1 investment } \\
\hline 0 & $\mathrm{D}$ & $\mathrm{D}$ & $\mathrm{D}$ & $\mathrm{D}$ & $\mathrm{D}$ & $\mathrm{D}$ & $\mathrm{D}$ & $\mathrm{D}$ \\
\hline 1 & 0.39 & 0.48 & 0.21 & 0.37 & 0.65 & 0.84 & 2.54 & 1.80 \\
\hline 2 & 0.81 & 1.00 & 1.11 & 2.50 & 1.01 & 1.04 & 2.46 & 1.96 \\
\hline 3 & 0.68 & 0.77 & 0.96 & 1.10 & 0.65 & 0.96 & 1.53 & 1.10 \\
\hline Total & 1.88 & 2.25 & 2.29 & 3.97 & 2.31 & 2.85 & 6.52 & 4.85 \\
\hline \multicolumn{9}{|c|}{ Share of LBD employment } \\
\hline 0 & 1.12 & 1.11 & 1.24 & 1.59 & 1.31 & 1.31 & 1.24 & 1.39 \\
\hline 1 & 3.02 & 3.02 & 3.01 & 2.93 & 3.20 & 2.85 & 2.69 & 2.87 \\
\hline 2 & 3.01 & 2.84 & 2.79 & 2.76 & 2.71 & 2.89 & 2.65 & 2.89 \\
\hline 3 & 2.53 & 2.75 & 2.64 & 2.58 & 2.55 & 2.45 & 2.71 & 2.55 \\
\hline Total & 9.67 & 9.72 & 9.68 & 9.86 & 9.77 & 9.50 & 9.29 & 9.70 \\
\hline \multicolumn{9}{|c|}{ Contribution to net employment growth } \\
\hline 0 & & 61.50 & 35.23 & 61.29 & 28.28 & 33.78 & 123.97 & 58.94 \\
\hline 1 & & 103.93 & 54.31 & 66.49 & 48.70 & 40.81 & 139.17 & 70.65 \\
\hline 2 & & -6.42 & -3.47 & -6.66 & -3.58 & -4.85 & -17.12 & -1.59 \\
\hline 3 & & -11.16 & -3.00 & -5.49 & -3.45 & -3.94 & -14.84 & -1.64 \\
\hline Total & & 147.86 & 83.06 & 115.63 & 79.95 & 65.80 & 231.18 & 126.37 \\
\hline
\end{tabular}

Note: D indicates that the statistic is suppressed in order to avoid disclosing data for individual companies.

\section{The Contribution of Exit}

As discussed above, we are also interested in the contribution of entry and exit to capital and investment dynamics. The results and discussion in the prior subsection make clear, however, that ACES is not well suited to a study of the contribution of entry since new firms seem to enter ACES with a lag. Since we cannot adequately measure entry in this context we do not adopt the capital creation and destruction measures used in our plant-level analysis. ACES can be used to study the contribution of exit to capital destruction. Thus, we undertake a more limited analysis and simply try to quantify the value of assets that are impacted by firm exit.

For this exercise, we are looking at firm rather than plant exit. In this context, we consider two alternative types of firm exit. Using the LBD we can differentiate between firms that disappear from the data but whose establishments (or subset of those establishments) continue to operate under a different firm, and firms whose establishments cease to be active. We call the latter cases "pure deaths" and the former "FIRMID deaths." We note that ACES does not provide sufficient information to investigate what happens to the capital assets for establishment deaths for multi-unit firms. The latter is a related topic worthy of further investigation.

Table 12.10 shows the current dollar value of fixed assets for both pure and FIRMID deaths from 1993 to 1999. These numbers give us the fixed 
Disposition of assets from firm closures and used capital expenditures (billions of current \$)

\begin{tabular}{lrrrrrrr}
\hline & 1993 & 1994 & 1995 & 1996 & 1997 & 1998 & 1999 \\
\hline Fixed assets: Pure deaths & 10.1 & 26.7 & 8.3 & 19.1 & 25.6 & 30.5 & 22.3 \\
Fixed assets: FIRMID deaths & 124.9 & 145.0 & 166.1 & 284.9 & 295.1 & 270.4 & 348.5 \\
Year $t+1$ used capital expenditures & 30.7 & 35.0 & 34.6 & 31.2 & 63.5 & 42.0 & 62.7 \\
$\begin{array}{l}\text { Year } t+1 \text { other additions and } \\
\quad \text { acquisitions }\end{array}$ & 38.3 & 67.8 & 101.6 & 123.0 & 152.6 & 186.6 & 173.3 \\
\hline
\end{tabular}

Note: This table is based on our calculations using only ACES- 1 firms that reported positive capital expenditures. Thus, our totals are slightly below published estimates. We chose to use only this subsample due to data quality considerations. The Census Bureau does not publish either fixed assets or other additions and acquisitions. Therefore, these fields were only edited for ACES-1 firms with positive capital expenditures.

assets from ACES for the last year the firm operated. FIRMID deaths can include mergers and other activities that result in the disappearance of an active FIRMID in the LBD with little or no real consequences for the operating establishments the firm controlled.

To put these numbers into perspective and also to raise a related measurement issue, we consider possible outcomes for the assets of dying firms. These assets can be purchased by domestic firms in used capital markets, acquired by domestic firms through merger and acquisition (M\&A) activity, exported, or scrapped. On the ACES form, the Census Bureau asks firms to give two pieces of information that shed light on how the assets of dying firms are disposed. First it asks for expenditures on used capital. This would capture any assets of dying firms that are purchased in used capital markets. But these markets also deal in capital sold by continuing firms. So not all used capital expenditures captured on the ACES would be from dying firms.

Table 12.10 shows that the value of assets at FIRMID deaths far exceeds that of pure deaths. Most of these assets are absorbed by the firms that acquire the establishments of the dying FIRMID businesses. The Census Bureau asks firms to include as used capital expenditures assets acquired through M\&A activity in cases that the firm considers these capital expenditures (i.e., when the firm maintains depreciation or amortization accounts for the acquired assets). If assets acquired through M\&A activity are not considered capital expenditures, the Census Bureau asks ACES respondents to enter the value of these assets under "Other Additions and Acquisitions."

Thus, it should be the case that those assets impacted by firm deaths (pure and FIRMID deaths) that remain in use by other domestic firms should be reflected in the used expenditures and other additions and acquisitions numbers in ACES. The last two rows of table 12.10 show the total used capital expenditures and other additions and acquisitions, respec- 
tively, in the ACES for the year following the death of the firms whose fixed assets are reported in the first two rows of the table. The idea here is that we should see deaths in year $t$ be reflected in increased assets in year $t+1$ for the firms acquiring the assets of the dying firms. Thus, in this context, the sum of the first two rows can be taken to represent the stock of used assets available from firm deaths. The last two rows represent the domestic absorption of these assets plus assets sold on used capital markets by continuing firms. Hence, the last two rows serve as an upper bound on the absorption of used assets from dying firms.

We see from the table that, depending on the year, between 51 percent and 78 percent (64 percent on average) of the assets of pure and FIRMID deaths are absorbed either through M\&A activity, in the case of FIRMID deaths, or outright purchases of used capital. The ACES data suggest that the total absorption is substantially below the amount of fixed assets made available through FIRMID deaths (i.e., the transfer of assets through M\&A activity). Moreover, much of this absorption is measured via the "other additions and acquisitions" category. This category is not included in published capital expenditures statistics, and thus users of the published statistics would miss much of these expenditures.

In short, this preliminary investigation reveals two different but related problems in the treatment of firm exits. First, the total value of assets associated with firm exits (either pure deaths or FIRMID deaths) is not captured through measures of used capital expenditures or through measures of other acquisitions. An open question is whether this measurement gap reflects capital that is scrapped but not captured in the measurement of capital and depreciation. A related question here which we could not investigate is the possible scrapping of capital from establishments that shut down that are part of multi-unit firms. In addition to the measurement gap we have detected, the composition of capital acquisition raises further questions. Much of the transfer of assets appears to be captured in ACES via an unpublished category denoted as other acquisitions. The fact that these capital transfers are apparently not captured in used expenditures and, in turn, are not part of published statistics raises further questions about the treatment of firm exits in the measurement of capital.

The work reported here is just a small step toward a better understanding of how the assets of dying firms are disposed. Its clear there is much more to be learned about how firm entry and exit affect the stock and flows of capital. Understanding the role for firm dynamics on capital is important from both the micro and macro perspectives. Further progress will require addressing several difficult measurement issues such as the valuation of the fixed assets stock versus the cost of acquiring them, the role of exports of used assets, and price deflators to both new and used capital.

We also believe that the measurement problems induced by exits do not simply imply measurement error in the average level of the capital stock 
but likely cause problems in the measurement of cyclical variations in the capital stock as well as capital utilization. As we have emphasized, studies of firm dynamics highlight the volatile nature of firm-level adjustment whether in terms of entry and exit or in terms of lumpy adjustment of capital. Important for this point is the fact that establishment exits are highly countercyclical. Accordingly, the scrappage rate of capital as well as the reallocation rate of capital is not just a constant but likely varies across industries, time periods, and types of businesses. A related open question is the utilization rates of capital that are engaged in capital reallocation. Presumably it takes time and resources to reallocate capital (even if it is primarily a change of ownership rather than the physical location of the capital), and utilization rates during such periods might be very low. All of these factors suggest that the problems induced by exits are not likely to be fixed with simple adjustment factors to depreciation rates but will require direct data collection and analysis.

\section{Summing Up Firm-Level Evidence}

This brief exploration of the micro properties of the distribution of firmlevel investment yields a number of insights. First, it is difficult to apply perpetual inventory measurement and, in a related fashion, difficult to use ACES as a panel data set given the annual panel rotation. Second, ACES appears to get entrants with a lag. Third, there are dramatic differences in the patterns of investment by firm age. Young businesses have much greater investment rates than do mature businesses. This latter pattern mimics the patterns of employment growth. However, unlike for employment, young businesses account for a relatively small fraction of gross investment. This finding is partly because young businesses have much smaller capital stocks than do more mature businesses, so even high gross investment rates contribute relatively little to aggregate gross investment. Moreover, for employment growth we tend to find mature businesses exhibiting little growth, while for capital we still find that mature businesses exhibit robust positive gross investment. Finally, we find that there are substantial assets associated with firm exit (via either exit of all plants or acquisition).

\subsection{Concluding Remarks}

Micro and macro data integration should be an objective of economic measurement, as it is clearly advantageous to have internally consistent measurement at all levels of aggregation - firm, industry, and aggregate. Such internal consistency permits transparent accounting of the sources of changes in aggregates, whether due to economic factors or problems of measurement, and it permits micro-level analysis in a context where the aggregate implications can be clearly investigated. There are a rich range of firm characteristics over which recent research suggests it is useful to de- 
compose aggregate changes such as age and size of business as well as decomposing the contribution of continuing, entering, and exiting businesses. In spite of these apparently compelling arguments, there are few measures of business activity that achieve anything close to micro/macro data integration. The measures of business activity that are arguably the worst on this dimension are capital stocks and flows. In this chapter, we have documented and quantified the widely different approaches to the measurement of capital from the aggregate (top-down) and micro (bottomup) approaches.

Capital stock and flow aggregates are based on a top-down, supply-side approach. Measures of the domestic production, exports, and imports of capital goods yield reasonably accurate measures of domestic supplies of these commodities. These supply totals are the strength of the top-down approach. Somewhat more challenging is to allocate the domestic supply across personal consumption, government consumption, and fixed business investment by detailed asset class since there are limited expenditure data available by these categories by detailed asset class. Still, the top-down approach arguably yields reasonably accurate measures of aggregate capital stocks and flows by detailed asset classes (to be cautious, there are inherently difficult problems with measuring investment deflators for capital goods and depreciation given both data limitations and difficult conceptual problems).

The weakest link in the top-down approach is not the capital stocks and flows by asset class but the capital stock and flows by detailed asset type and by industry. Currently, this latter allocation is based upon indirect methods and very strong assumptions about the relationship between asset use by industry and the occupational distribution of an industry. These problems are most severe for allocating equipment investment-for example, in the most recently released 1997 capital flows table, about 85 percent of the total value of equipment investment is allocated across industries based upon the occupational distribution of employment.

The core problem has been the lack of direct measures of detailed asset use by industry. Recently, there have been some improvements in the collection of capital expenditures at the firm level for all sectors with the development of the ACES. However, data from the ACES are only beginning to be used in the national accounts. We have taken advantage of these new data in our analysis in this paper to explore the limitations of the top-down approach for measuring capital stocks and flows by industry.

In exploring the new ACES data, we have also learned about the many limitations of building up capital expenditures data from the bottom up. For one, firms that are asked to break out their assets by industry too often truncate the set of industries for which they report (where we know from other sources that the firms are engaged in activity in those industries). For another, expensing and leasing issues plague measurement of capital expenditures by firms, particularly for some types of assets. 
In this chapter, we develop a hybrid approach to allocating assets by industry that attempts to take advantage of the strengths of both the topdown and bottom-up approach and also minimizes (or at least adjusts for) the limitations of each of the approaches. We believe our hybrid approach has promise for improved measurement of capital stocks and flows by asset and industry. Moreover, our hybrid methodology has the promise of making the micro and macro data more internally consistent so that there is a greater ability to conduct internally consistent analyses of capital stocks and flows at the micro and the macro levels. Our actual implementation of this hybrid methodology has numerous limitations of its own that could be improved upon by further study as well as by improved source data and improved integration of the business data at the Census Bureau.

A closely related objective of this chapter is to characterize the state of economic measurement for micro-level capital stocks and flows. Measurement from the bottom up is important for improving the aggregates, as discussed above, but is also important in its own right. Analysts have increasingly been using longitudinal business-level data sets to study business dynamics even when the objective is to understand aggregate fluctuations in business activity.

Creating a data infrastructure that permits high-quality analysis at the micro level poses many challenges. Panel rotation of surveys makes measurement of capital stocks by perpetual inventory methods difficult. Moreover, the data collected are quite sparse at the micro level on an annual basis - at best, data are collected by broad asset class annually. Among other things, this makes generating investment price deflators and depreciation rates that are firm specific difficult if not impossible. There has also unfortunately been some deterioration in the collection of capital stocks and flows at the establishment level for the manufacturing sector in the ASM. The deterioration of the ASM capital data is unfortunate since the ASM has successfully been linked longitudinally, permitting a rich range of analysis of business dynamics. As we have emphasized, while ACES has yielded an improvement on some dimensions, ACES has many limitations as a longitudinal microdata set given the sampling procedures used for ACES (e.g., the annual sample rotation and the underrepresentation of entrants and young businesses).

In spite of these measurement challenges at the micro level, the facts that emerge from the micro analysis are quite striking. Investment activity at the business level is very lumpy and in turn very heterogeneous. A large fraction of businesses in any given year have literally zero investment while a small fraction of businesses have large investment spikes. These investment spikes account for a large fraction of aggregate investment and also account for a large fraction of the cumulative investment of the individual business over a long period of time. All of this lumpiness implies that some businesses are shrinking their capital stocks (via depreciation primarily) while others are expanding their capital stocks substantially. The implied 
heterogeneity of capital growth rates across businesses implies that the allocation of capital across producers is constantly in a state of flux. Moreover, the entry and exit of businesses yields important contributions to this reallocation of capital inputs across production sites. A related dynamic is that young businesses have high failure rates but conditional on survival have very high average investment (and output and employment) growth rates. Putting all of these factors together suggests that the aggregate dynamics are driven by a complex set of factors and that understanding the aggregates requires decomposing the aggregate changes into the contribution of businesses with zero investment versus those with investment spikes, the contribution of entry and exit, and the contribution of young versus more mature businesses. Moreover, our findings suggest that the contribution of these factors is time varying both across cycles and across secular episodes. For example, the investment boom in the late 1970s is more associated with a fall in what we denote as gross capital destruction (capital contraction by continuing and exiting businesses) than gross capital creation, while the investment booms in the 1980s and 1990s are more associated with increases in gross capital creation.

In addition to raising interesting questions about the driving forces for micro and macro investment dynamics, our preliminary findings raise an interesting question about the treatment of plant and firm exits in the measurement of capital. The standard treatment of the service life of an asset ignores plant and firm exit issues. That is, the service life is given by the technological use of the asset and neglects the role of plant and firm exits. The current methods used to estimate capital stocks do take into account the impact of secondary markets on the efficiency schedules in a crude fashion with some adjustments for selection bias. Still, at the end of the day we don't know very much about the implications of firm exits and capital reallocation for capital measurement. We make some progress on determining the extent of this problem by undertaking some exercises that compare the assets from exiting businesses with used capital expenditures and estimates of other acquisitions that in principle should capture the capital reallocation from firm exits. We find that the value of assets released into the economy from firm exits substantially exceeds our upper-bound estimates of domestic absorption of used assets through purchases and acquisitions. While there are a number of measurement limitations from our analysis, we believe this issue deserves further attention and also highlights the importance of micro/macro data integration. One reason that this is important is that firm and plant exits are highly cyclical and vary considerably across industry so that any measurement error induced has consequences for our understanding of variation over time and industries.

We believe these micro properties provide prima facie evidence that understanding aggregates requires the micro/macro internal consistency. However, we clearly recognize that our analysis of the properties of the 
micro distributions have limitations, given the limitations in the microdata (and the associated measures at the micro level), so these inferences should be treated with appropriate caution.

An open question is what can be done to improve micro/macro data consistency - in general and in particular for the case of capital. From our vantage point, considerable progress could be made if (a) there were a concerted effort to develop the type of hybrid methodology proposed here to integrate the micro and the macro approaches to capital measurement, and (b) the survey design for the collection of the data on capital stocks and flows (primarily by the ASM and ACES) clearly recognized that one of the uses of the data is for microdata analysis and closely related micro/macro data integration. As such, statistical agencies should consider changes to surveys of business investment, such as the ACES, that put increased attention on entrants and young business and rethink sample rotation strategies to enhance longitudinal analysis.

\section{Appendix}

First collected in 1993, the Annual Capital Expenditure Survey (ACES) is designed to tabulate industry level totals for capital investment, split out into equipment and structures, new and used. Its coverage includes nearly the entire nonfarm private-sector economy. In particular, prior to 1999, capital expenditure data were collected and published on nearly 100 industries at the two- to three-digit SIC level of detail, and since 1999 data have been collected on a NAICS basis, with about 134 three- to four-digit nonfarm industries. An additional "industry" is provided for reporting a firm's structures and equipment expenditures that serve multiple industries (e.g., headquarters, regional offices, and central research laboratories). From 1993 to 1995, the ACES sample consisted of 27,000-30,000 companies with five or more employees, and in 1993 and 1995, an abbreviated survey form (ACES-2) was sent to 15,000 companies with under five employees or no employees at all (i.e., nonemployers). Since 1996, the sample has consisted of roughly 32,000-44,000 companies with employees and 12,000-15,000 nonemployers. The former group receives the long-form version of the survey (ACES-1), while the others receive the abbreviated ACES-2.

Recipients of both these forms are asked their firm-level expenditures on new and used structures and equipment. The ACES-2 form essentially stops there. Firms receiving the ACES-1, however, are also asked to report firm-level totals on the book value of assets, depreciation, and retirements, new structures and equipment acquired under capital lease agreements entered into during the survey year, and capitalized interest incurred to pro- 
duce or construct new fixed assets during the survey year. Most important, these firms are asked to provide capital expenditures data for each industry in which they had activity and to classify these expenditures as new or used and as structures, equipment, or other.

In certain years, recipients of the ACES-1 are asked to further break down their investment expenditures by type of structure and by type of equipment, in addition to breaking them down by industry. For example, in 1994, firms were asked to provide detail on their structure expenditure, and in 1998 they were asked for detail on both structure and equipment expenditure. In 1998, ACES collected data on expenditures on twenty-nine distinct categories of structures, twenty-six distinct categories of equipment. The 2003 ACES, which was in the field at the time of this research and was published in mid-2005, also collected the full structure and equipment detail by industry.

As above, we focus on just the 1998 ACES. Overall, 45,997 firms were sampled in 1998, with 33,815 employers receiving the ACES- 1 and the 12,182 nonemployers receiving the ACES-2. Because we are interested in investment by industry and by asset type, we focus on just the recipients of ACES-1. Unfortunately, as we noted above, the capital expenditure accounted for by nonemployers - totaling $\$ 95$ billion, or about 9.7 percent of the national total - is allocated to neither industry nor asset type in the ACES, which is an important limitation and an important difference from the BEA estimates. ${ }^{35}$ It is also important to note that this missing investment is likely to affect some industries (and probably some asset types) more than others. In any event, of the 33,815 firms that were sent ACES-1 forms, 27,710 (82 percent) responded with quality data that entered into the published aggregates. The employer universe accounted for $\$ 879$ billion of (weighted) capital expenditures. With the $\$ 95$ billion of investment by nonemployers, the ACES measured \$973.6 billion in total capital expenditure in $1998 .^{36}$

While we note several issues with the data collected in ACES in section 12.2 , one important phenomenon is that survey respondents truncate the number of industries that they report relative to the number of industries in the BR. To document this phenomenon, we examine a subsample of 26,470 ACES-1 reporters. ${ }^{37}$ Employing ACES definitions of industries, we

35. In 1995, when firms with one to four employees also received the ACES-2, almost 18 percent of national investment was unallocated to industry by ACES.

36. In contrast, the FRTW recognized $\$ 1,067.1$ billion in investment and the CFT $\$ 1,160.7$ billion, though it is important to note that the industrial scope and the assets captured are somewhat different between these three sources, in addition to some of the other conceptual differences discussed above.

37. For various reasons, 1,024 firms are excluded from the original sample: Most are dropped for not having industries with positive payroll in the BR. Others are dropped for having activity in various out-of-scope industries, such as agricultural production. Including these firms would complicate the analyses. Still other firms are dropped for having establish- 
find that these firms acknowledged 1.35 industries in the ACES on average, while the same firms had nonzero payroll in 1.85 industries according to the Business Register, or 37 percent more. The omitted industries however appear to be among these firms' lesser industries, at least on average. In particular, the unacknowledged industries accounted for just 11.0 percent of the weighted payroll. ${ }^{38}$ Even so, if capital expenditures are distributed identically to payroll (hypothetically), this implies that total investment in the reported industries would be 12 percent too high on average (i.e., 1/ $[1-0.110]=1.124) \cdot{ }^{39}$ In terms of the 8,122 firms that actually operated in more than one industry (according to the BR), they acknowledged an average of 2.08 industries in the ACES, while the BR had nonzero payroll in 3.78 industries, or 82 percent more. Here, the unacknowledged industries accounted for 16.8 percent of these firms' weighted payroll — suggesting an upward bias in the capital expenditures of the remaining industries of almost 20 percent on average. Industry truncation, therefore, appears to be a potentially serious concern.

Next, we explore whether certain industries go unreported in ACES more often than others. Table 12A.1 lists the top ten industries in terms of how frequently these 26,470 firms failed to acknowledge them and in terms of the weighted payroll at stake (in billions of 1998 dollars). By either measure, Wholesale Trade of Durable Goods (Except Motor Vehicles) is the top omitted industry, and the related Wholesale Trade of Nondurable Goods (Except Groceries and Petroleum Products) is not very far behind. This is not an entirely new finding. In their attempt to reconcile why firms responding to both the 1996 ACES and the 1996 ASM reported more capital expenditure in manufacturing on their ACES form, Becker and Dunne (1999) found that firms primarily engaged in manufacturing regularly failed to acknowledge their wholesaling activities in the ACES, presumably misallocating that expenditure to their manufacturing industries instead. It seems that any industry that is secondary to a firm's primary activity runs a greater risk of being shortchanged in ACES. And to the extent that some industries are "inherently secondary," they may be systematically shortchanged by ACES. Indeed, some of the other industries in table 12A.1 might certainly be deemed "support" industries, such as Engineering, Accounting, Research, and Management Services as well as Computer Programming, Data Processing, and Other Computer Services.

ments in the BR that have insufficient SIC codes and could not be reasonably assigned proper codes. These excluded firms account for 6.4 percent of the weighted investment in the original sample.

38. While relatively rare, firms sometimes acknowledge industries that are not in the BR. Here, 3.2 percent of weighted capital expenditure appeared in such industries.

39. This of course presumes that firms correctly report firm-level capital expenditure and distribute it over too few industries. Another possibility is that firms underreport the firmlevel total, by omitting the investment in the unacknowledged industries. Given the structure of the ACES survey, however, this scenario doesn't seem likely. 
Table 12A.1

Industries most often omitted by firms in the ACES

\begin{tabular}{|c|c|c|}
\hline \multicolumn{2}{|c|}{ Rank/Industry } & \multirow{2}{*}{$\begin{array}{c}\text { Frequency } \\
1,301\end{array}$} \\
\hline 1 & Wholesale trade of durable goods (except motor vehicles) & \\
\hline 2 & Holding, charitable trusts, and other investment offices & 1,251 \\
\hline 3 & Engineering, accounting, research, and management services & 1,137 \\
\hline 4 & Other retail dealers $\mathrm{s}^{\mathrm{a}}$ & 851 \\
\hline 5 & $\begin{array}{l}\text { Wholesale trade of nondurable goods (except groceries and } \\
\text { petroleum products) }\end{array}$ & 748 \\
\hline 6 & Business services, $\mathrm{NEC}^{\mathrm{b}}$ & 646 \\
\hline 7 & Real estate offices & 509 \\
\hline 8 & Other health care and allied services ${ }^{c}$ & 399 \\
\hline 9 & $\begin{array}{l}\text { Computer programming, data processing, and other } \\
\text { computer services }\end{array}$ & 380 \\
\hline \multirow[t]{2}{*}{10} & Social services (including child day care and residential care) & 370 \\
\hline & & $\begin{array}{l}\text { Weighted payroll } \\
\text { (billions of } 1998 \text { dollars) }\end{array}$ \\
\hline 1 & Wholesale trade of durable goods (except motor vehicles) & 31.5 \\
\hline 2 & $\begin{array}{l}\text { Engineering, accounting, research, and } \\
\text { management services }\end{array}$ & 24.0 \\
\hline 3 & $\begin{array}{l}\text { Wholesale trade of nondurable goods (except groceries and } \\
\text { petroleum products) }\end{array}$ & 18.6 \\
\hline 4 & Business services, $\mathrm{NEC}^{\mathrm{b}}$ & 15.6 \\
\hline 5 & Other retail dealers ${ }^{\mathrm{a}}$ & 15.2 \\
\hline 6 & Securities and commodity brokers and services & 13.3 \\
\hline 7 & $\begin{array}{l}\text { Computer programming, data processing, and other } \\
\text { computer services }\end{array}$ & 12.2 \\
\hline 8 & Measuring, analyzing, and controlling instruments; etc. ${ }^{\mathrm{d}}$ & 9.9 \\
\hline 9 & $\begin{array}{l}\text { Fabricated metal products (except machinery and } \\
\text { transportation equipment) }\end{array}$ & 9.2 \\
\hline 10 & Other health care and allied services ${ }^{\mathrm{c}}$ & 8.7 \\
\hline
\end{tabular}

Note: $\mathrm{NEC}=$ not elsewhere classified.

${ }^{a}$ Excludes retail stores dealing in general merchandise (including department stores), food, apparel \& accessories, and shoes

'Includes all of SIC 73 except equipment rental and leasing (SIC 735) and computer programming, data processing, and other computer services (SIC 737).

${ }^{\mathrm{C}}$ Includes medical and dental laboratories, kidney dialysis centers, specialty outpatient facilities NEC, and other NEC activities.

${ }^{\mathrm{a}}$ SIC 38. Also includes photographic, medical, and optical goods, as well as watches and clocks.

A corollary to the above is that some industries may be "inherently primary" and therefore systematically have too much capital expenditure attributed to them. In table 12A.2, we list the top ten types of firms (according to their primary industry) that are most likely to provide insufficient industry detail on the ACES, as measured by the percent of their collective payroll in industries unacknowledged on their forms. Two things are im- 


\begin{tabular}{|c|c|c|c|}
\hline \multirow{2}{*}{\multicolumn{2}{|c|}{ Rank/Firm's primary industry }} & \multicolumn{2}{|c|}{$\begin{array}{l}\text { Payroll unacknowledged } \\
\text { in ACES }\end{array}$} \\
\hline & & Percent & Billions of 1998 dollars \\
\hline 1 & Water supply and sanitary service (SIC 494-497) & 46.2 & 3.2 \\
\hline 2 & Suppressed & 39.0 & $\mathrm{D}$ \\
\hline 3 & Holding, charitable trusts, and other investment offices (SIC 67) & 37.9 & 4.1 \\
\hline 4 & Measuring, analyzing, and controlling instruments, etc. (SIC 38) & 34.0 & 12.5 \\
\hline 5 & Miscellaneous services (SIC 89) & 33.5 & 1.5 \\
\hline 6 & Other health care and allied services (SIC 807 and 809) & 30.0 & 5.1 \\
\hline 7 & Computer and office equipment (SIC 357) & 29.0 & 5.3 \\
\hline 8 & $\begin{array}{l}\text { Communications equipment and electronic components and } \\
\text { equipment (SIC 36) }\end{array}$ & 24.7 & 19.7 \\
\hline 9 & Other depository institutions (SIC 608 and 609) & 21.4 & 1.0 \\
\hline 10 & $\begin{array}{l}\text { Wholesale trade of nondurable goods (except groceries and } \\
\text { petroleum products) }\end{array}$ & 21.1 & 10.0 \\
\hline
\end{tabular}

Note: D indicates that the statistic is suppressed in order to avoid disclosing data for individual companies.

mediately apparent. First, some of the industries here are also among those in table 12A.1. This finding suggests that these industries experience offsetting effects - of having unreported capital expenditure by some firms and overreported expenditure by others. It could also indicate that there are some discrepancies in how these firms classify their primary industry and how the Census Bureau classifies it. Second, more manufacturing industries appear here than in the prior table, and they are relatively high-tech industries at that. And not only do these particular manufacturing firms miss a large portion of their activities in percentage terms, but these activities account for quite a bit of weighted payroll.

Isolating the firms in just these manufacturing industries, we examined the industries that they were least likely to acknowledge in ACES despite having payroll in them (according to the BR). Perhaps not surprisingly, the single industry that these firms failed to report more than all others is Wholesale Trade of Durable Goods, which was also the top industry in table 12A.1. ${ }^{40}$ The point is that manufacturing firms tend not to think of themselves as being engaged in wholesale activity. Other unreported industries high on the list of these high-tech firms are Holding, Charitable Trusts, and Other Investment Offices (SIC 67); Engineering, Accounting, Research, and Management Services (SIC 87); and Computer Programming, Data Processing, and Other Computer Services (SIC 737).

40. In fact, these three manufacturing industries account for over 40 percent of the $\$ 31.5$ billion of the uncovered payroll in Wholesale Trade of Durable Goods seen in table 12.4. 


\section{References}

Autor, David H., Frank Levy, and Richard J. Murnane. 2003. The skill content of recent technological change: An empirical explanation. Quarterly Journal of Economics 118 (4): 1279-1333.

Becker, Randy, and Timothy Dunne. 1999. Annual Capital Expenditure Survey (ACES) and Annual Survey of Manufactures (ASM) comparison. Washington, DC: Center for Economic Studies. Memorandum, March.

Caballero, Ricardo, Eduardo Engel, and John C. Haltiwanger. 1995. Plant-level adjustment and aggregate investment dynamics. Brookings Papers on Economic Activity, Issue no. 2:1-39.

Cooper, Russell, and John C. Haltiwanger. 2000. On the nature of capital adjustment costs. NBER Working Paper no. 7925. Cambridge, MA: National Bureau of Economic Research.

Cooper, Russell, John C. Haltiwanger, and Laura Power. 1999. Machine replacement and the business cycle: Lumps and bumps. American Economic Review 89:921-46.

Davis, Steven, John C. Haltiwanger, and Scott Schuh. 1996. Job creation and destruction. Cambridge, MA: MIT Press.

Doms, Mark, and Timothy Dunne. 1998. Capital adjustment patterns in manufacturing plants. Review of Economic Dynamics 1:409-29.

Doms, Mark, Ron S. Jarmin, and Shawn D. Klimek. 2004. IT investment and firm performance in U.S. retail trade. Economics of Innovation and New Technology 13 (7): 595-613.

Foster, Lucia, John C. Haltiwanger, and Namsuk Kim. 2005. Gross job flows from the Annual Survey of Manufactures: 1993-98. Washington, DC: Center for Economic Studies. Mimeograph.

Foster, Lucia, John C. Haltiwanger, and C. J. Krizan. 2001. Aggregate productivity growth: Lessons from microeconomic evidence. In New developments in productivity analysis, ed. Edward Dean, Michael Harper, and Charles Hulten, 303-63. University of Chicago Press.

2002. The link between aggregate and micro productivity growth: Evidence from retail trade. NBER Working Paper no. 9120. Cambridge, MA: National Bureau of Economic Research. August.

Haltiwanger, John C., and C. J. Krizan. 1999. Small business and job creation in the United States: The role of new and young businesses. In Are small firms important? Their role and impact, ed. Zoltan Acs, 79-97. Boston: Kluwer Academic.

Hulten, Charles, and Frank Wykoff. 1981. The estimation of economic depreciation using vintage asset prices: An application of the Box-Cox power transformation. Journal of Econometrics 15:367-96.

Jarmin, Ron, and Javier Miranda. 2002. The longitudinal business database. Washington, DC: Center for Economic Studies Working Paper no. WP-02-17.

Jorgenson, Dale, Mun Ho, and Kevin Stiroh. 2005. Growth of U.S. industries and investments in information technology and higher education. In Measurement of capital in the new economy, ed. Carol Corrado, John Haltiwanger, and Daniel Sichel. Chicago: University of Chicago Press, forthcoming.

Lawson, Ann, Kurt Bersani, Mahnaz Fahim-Nader, and Jiemin Guo. 2002. Benchmark input-output accounts of the United States, 1997. Survey of Current Business 82 (12): 19-109.

Meade, Douglas, Stanislaw Rzeznik, and Darlene Robinson-Smith. 2003. Business investment by industry in the U.S. economy for 1997. Survey of Current Business 83 (11): $18-70$. 
Stiroh, Kevin J. 2004. Reassessing the impact of IT in the production function: A meta-analysis and sensitivity tests. New York: Federal Reserve Bank of New York. Mimeograph.

U.S. Bureau of Economic Analysis. 1999. Fixed reproducible tangible wealth in the United States, 1925-1994. Washington, DC: U.S. Government Printing Office.

U.S. Census Bureau. 2000. Annual capital expenditures 1998. Washington, DC: U.S. Department of Commerce.

Wilson, Daniel J. 2003. Embodying embodiment in a structural, macroeconomic input-output model. Economic Systems Research 15 (3): 371-98.

. 2004. Investment behavior of U.S. firms over heterogeneous capital: A snapshot. FRBSF Working Paper no. 2004-21. October. San Francisco: Federal Reserve Bank of San Francisco.

Wolff, Edward. 2002. Computerization and structural change. Review of Income and Wealth 48 (2): 59-75. 
